\title{
Increased Costs to US Pavement Infrastructure from Future Temperature Rise
}

B. Shane Underwood ${ }^{a^{*}}$, Ph.D., Zack Guido ${ }^{b}$, Ph.D., Padmini Gudipudi, Ph.D. ${ }^{c}, Y$ arden Feinberg ${ }^{d}$

a Assistant Professor, Arizona State University, School of Sustainable Engineering and the Built Environment, PO Box 875306, Tempe, AZ 85287-5306 USA Shane.Underwood@asu.edu, Phone: 1480965 1097, Fax: 14809650557

${ }^{b}$ Research Scientist, Institute of the Environment, University of Arizona, Tucson, AZ 85721 USA

${ }^{c}$ Postdoctoral Scholar, Arizona State University, School of Sustainable Engineering and the Built Environment, PO Box 875306, Tempe, AZ 85287-5306 USA pgudipud@asu.edu

${ }^{d}$ Undergraduate Researcher, Arizona State University, School of Sustainable Engineering and the Built Environment, PO Box 875306, Tempe, AZ 85287-5306 USA

\begin{abstract}
Roadway design aims to maximise functionality, safety, and longevity. The materials used for construction, however, are often selected on the assumption of a stationary climate. Anthropogenic climate change may therefore result in rapid infrastructure failure, and consequently, increased maintenance costs, particularly for paved roads where temperature is a key determinant for material selection. Here, we examine the economic costs of projected temperature changes on asphalt roads across the contiguous United States using an ensemble of 19 global climate models forced with RCP 4.5 and 8.5 scenarios. Over the past 20 years, stationary assumptions have resulted in incorrect material selection for $35 \%$ of 799 observed locations. With warming temperatures, maintaining the standard practice for material selection is estimated to add approximately US\$13.6, US\$19.0, and US\$21.8 billion to pavement costs by 2010, 2040, and 2100 under RCP4.5, respectively, increasing to US\$14.5, US\$26.3 and US\$35.8 for RCP8.5. These costs will disproportionately affect local municipalities that have fewer resources to mitigate impacts. Failing to update engineering standards of practice in light of climate change therefore significantly threatens pavement infrastructure in the US.
\end{abstract}

Climate change may have widespread impacts on road, water, rail, and air system ${ }^{1,2}$. These impacts will result from intense precipitation, heat/cold stress, and other non-physical challenges that degrade infrastructure quality and longevity ${ }^{1,3-8}$. Because these transportation systems constitute large civil investments (US\$7.7 trillion in assets and US\$45 billion annual expenditures ${ }^{9}$ ) and underpin an economic vibrancy (five trillion kilometers of public travel per year ${ }^{10}$ and private citizen expenditures equal to $8.9 \%$ of $\mathrm{GDP}^{9}$ ), the impacts may be substantial. Transportation infrastructure is built to last decades, but engineering protocols in the United States assume climate stationarity, which may result in accelerated degradation, and, consequently, increased costs. Additional costs are a concern since the American Society of Civil Engineers estimates that infrastructure needs US\$3.6 trillion in the next decade, with a large fraction of that currently unfunded $^{11}$. At present, engineers assume a stationary climate when selecting pavement materials, meaning that they may be embedding an inherent negative performance bias in pavements for decades to come. With warming trends observed and accelerating across the U.S. ${ }^{12}$, and with scientific consensus for future warming, continued use of such data will likely expose some areas to more rapid degradation ${ }^{13-16}$. 
The current standard of roadway design guides engineers to use climate data from 1964-1995 to select materials. We quantify the economic effects of the continued use of this climate record by examining the impacts of non-stationarity on the asphalt grade in asphalt pavements (constitute $90 \%$ of paved surfaces in U.S. and $99 \%$ worldwide ${ }^{17}$ ). This analysis makes important advancements from previous studies ${ }^{4,18-27}$. First, we carry out the economic analysis nationally, regionally, and on a state-by-state basis after incorporating local engineering practices in material selection. We base this analysis on an ensemble of global climate models (GCMs) to probabilistically examine the costs from greater maintenance and reduced pavement life, while also accounting for the distinct types of roadways. We show results regionally and by state and over several decades to highlight their geo-spatial-temporal nature and to provide insights on the infrastructure impacts to decision-makers. More details from the literature and the specific advancements made by this study are given in Supplementary Section 1.

In the U.S., asphalts are used per the Superpave Performance Grading (PG) system, which assigns a temperature-related grade based on the maximum and minimum temperatures between which that asphalt should exhibit adequate performance ${ }^{28}$. A typical grade might be PG64-22, which means that the asphalt is Performance Graded for temperatures between $64^{\circ} \mathrm{C}$ and $-22^{\circ} \mathrm{C}$. Since the asphalt grade is based on pavement temperature and linked to pavement performance, it serves as a direct indication of how climate impacts pavement performance. Determining the required low and high temperatures for any location involves calculating the average and standard deviation of the minimum pavement temperature and the maximum seven consecutive day pavement temperature over a multi-decade period. In practice, the climate record used for this purpose is 1966-1995 and the averages are statistically adjusted to account for extremely cold or hot years and rounded to standard $6^{\circ} \mathrm{C}$ grade increments. In pavement engineering, other climate records may be used for structural design, but even in these cases the 1966-1995 climate record is the one used to select the materials for the design analysis. Thus, adherence to this record does have a substantial impact on the design and long-term behavior of pavements even though other records may be used for part of the design process.

By using the stationary climate record, we find that asphalt grades are already being improperly determined in many parts of the U.S. Figure 1 shows locations from the United States Historical Climate Network where the required asphalt grade based on temperature data from 1966-1995 differs from the one based on data from 1985-2014. In total, 35\% of stations have a different high or low temperature grade (6\% high temperature only, $26 \%$ low temperature only, and $3 \%$ both high and low temperature). High temperature grade changes are the primary performance concern since these sites will experience faster degradation, require greater maintenance, and possibly lead to earlier reconstruction. Underestimates of the low temperature value suggest that the location has additional protection against low temperature cracking, but implies that agencies are paying higher costs for materials that withstand lower temperatures than currently exist. 


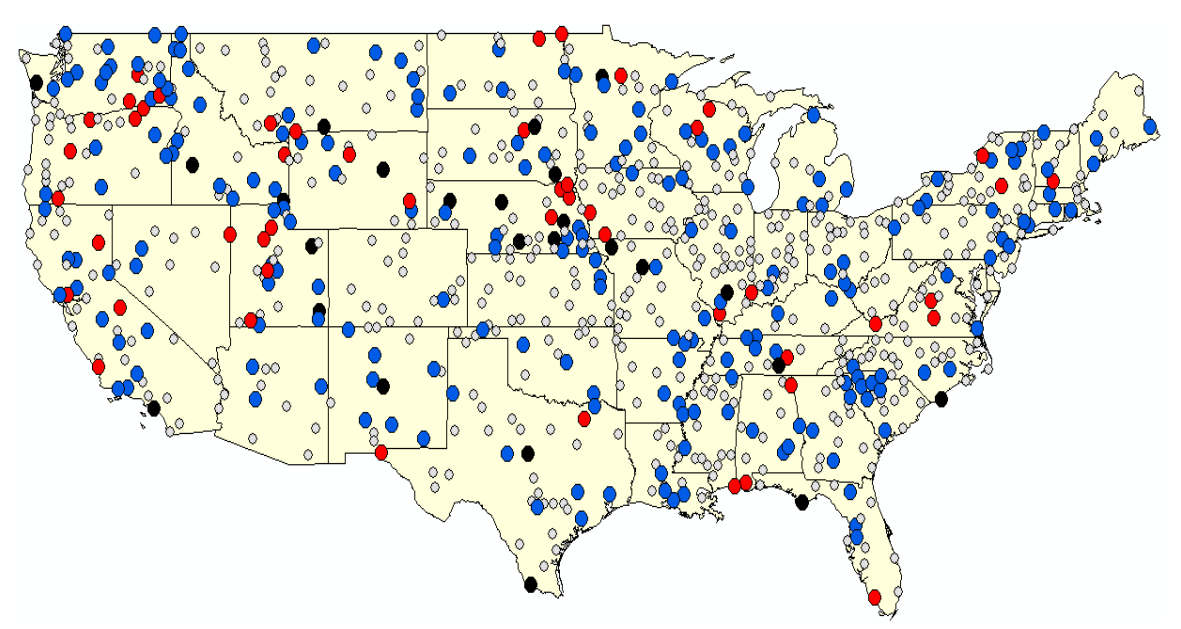

Figure 1. Weather stations evaluated to compare 1966-1995 climate database and 1985-2014 climate databases. Locations where the asphalt grade differs between the two datasets are colored in red, blue, and black. The red symbols show locations where the 1966-1995 data underestimate the high temperature grade required, whereas the blue symbols show those locations where the low temperatures were underestimated (estimated to be too low). The black symbols show both an overestimate and underestimate of the high and low temperature grades respectively. Locations with no change are left unfilled.

We examine future impacts by comparing the asphalt grades based on the 1966-1995 database to those determined by temperatures under future climate scenarios. The future scenarios are evaluated with a multi-model ensemble of one model run for each of 19 GCMs (see Supplementary Table 1) and for Representative Concentration Pathways (RCP) 8.5 and 4.5. Figure 2 maps the geospatial changes in the future pavement temperature for different periods of time based on the median of the model ensemble. We present results for RCP 8.5 here and RCP 4.5 in Supplementary Figure 1. In both scenarios, there is an increasing trend in the pavement temperature across the U.S. We show the effect of these temperatures on the required standard asphalt grade in Supplementary Figure 2. The locations with grade changes generally reflect what is shown in Figure 2. Locations where greater temperature changes are projected will need two standard asphalt temperature grade increments and those with less temperature increase needing one standard grade increment.

There are three factors that produce the unique high temperature change in Figure 2 and Supplementary Figure 1. First, is the use of the hottest 7-consecutive day temperature (instead of mean air temperature or highest temperature). Like what is reported elsewhere for heat waves in the U.S. ${ }^{32}$, the model ensemble predicts this increase will be the greatest in the upper Midwest extending through the Ohio Valley. Second, the variation in maximum 7-consecutive day temperature from one year to the next is expected to increase. This variability is already greater in the upper Midwest and Ohio Valley regions and the model ensemble predicts the variation to continue increasing. Third, the relationship between air temperature and pavement temperature is affected by sun position with southern latitudes receiving more direct sunlight. 
(a)

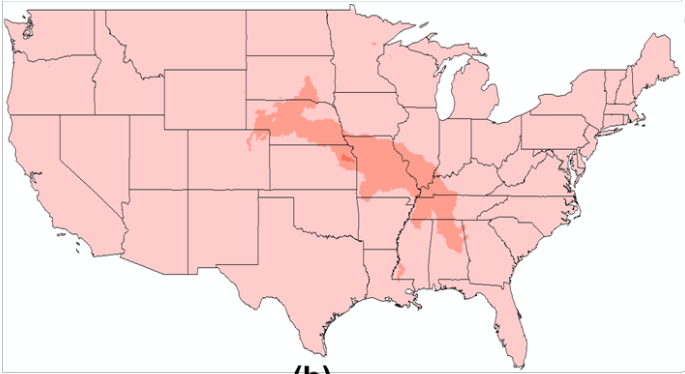

(b)

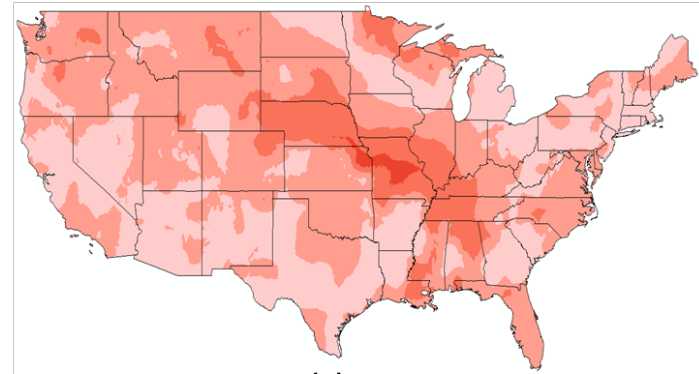

(c)

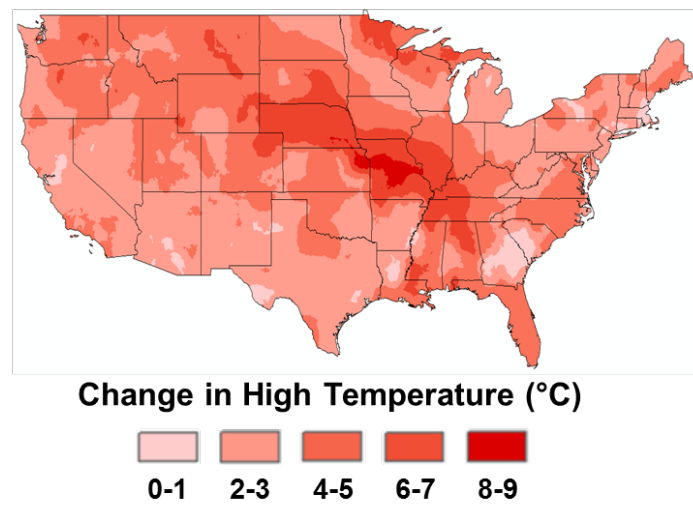

(d)

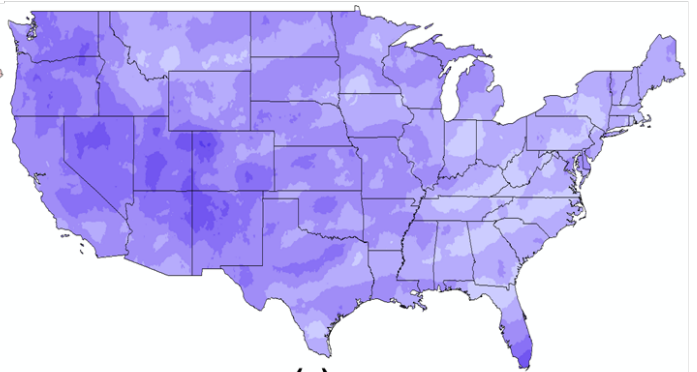

(e)

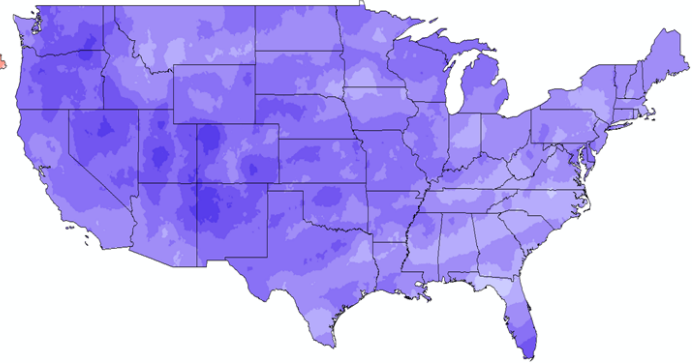

(f)

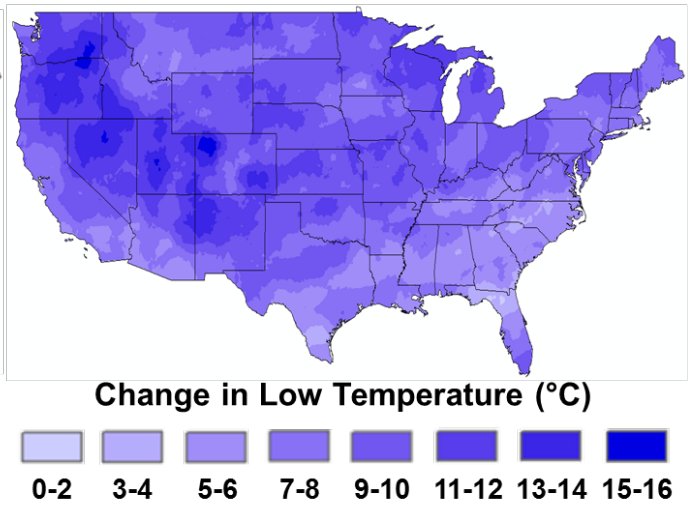

Figure 2. Expected median increases in pavement temperature based on the RCP 8.5 ensemble: (a-c) average 7-day maximum temperature and (d-f) average minimum temperature changes for 2010-39, 2040-69, and 2070-99 respectively relative to the 1966-1995 climatology. Darker colored contours indicate locations where the pavement temperatures will exceed current stationarity implied pavement temperatures by a greater level and thus experience greater performance impacts.

Under future scenarios the Ohio Valley and Southeast regions of the country are expected to experience the greatest pavement temperature. The Southwest and Pacific coastal regions show relatively little change in the high temperature ensemble median. However, the low temperature median is projected to increase, particularly along the Rocky Mountains. The model-to-model variation is high, but the trends are consistent across the model ensemble (Supplementary Section 3).

Changing pavement engineering policy and practice is slow and in the absence of adaptations, more frequent rehabilitation and maintenance will be required. We estimate that pavements originally intended to last 20 years will require rehabilitation after only 16-17 years when the pavement grade is wrong by one $6^{\circ} \mathrm{C}$ increment and $14-16$ years when the pavement grade is wrong 
by two $6^{\circ} \mathrm{C}$ increments (see Methods and Supplementary Section 4). These performance losses will bear a cost, which we estimate using life cycle cost analysis (LCCA).

Table 1 summarizes the net present value of all activities considered in the life cycle of the pavements when the correct asphalt grade is used (baseline case) and when the asphalt grade is wrong by one or two standard grades. Greater costs occur on the higher traffic roadways, but a greater impact as a percentage of the cost exists with the lower traffic roadways because construction represents a smaller proportion of the overall life cycle impact for lower traffic roadways. If the initial construction costs are not included in the cost estimate, also shown in Table 1 , then the percentage differences in costs are greater for the higher traffic roadways. Since lower traffic roadways are generally the responsibility of municipal agencies, it is likely that city and county road agencies will see a disproportionate economic impact to their road network. These agencies often work with more constrained budgets and fewer options to raise revenues for repairs and reconstruction, which further exacerbates the impacts.

Table 1. Impacts by Pavement Type when using the correct and incorrect asphalt grade [Percent Difference from Using the Correct Asphalt grade shown in brackets]. Bottom three rows of table show the cost impacts if the initial construction costs are not included in the NPV (note actual impacts carry slightly higher precision than shown in table so round-off difference may be present).

\begin{tabular}{|c|c|c|c|}
\hline $\begin{array}{c}\text { Roadway } \\
\text { Type }\end{array}$ & $\begin{array}{c}\text { Correct } \\
\text { Asphalt Grade }\end{array}$ & $\begin{array}{l}\text { Asphalt Grade Incorrect by One } \\
\text { Increment }\end{array}$ & $\begin{array}{c}\text { Asphalt Grade Incorrect } \\
\text { by Two Increments }\end{array}$ \\
\hline \multicolumn{4}{|c|}{ Net Present Cost $(U S \$ / \mathrm{km})$} \\
\hline Interstate & $1,183,702$ & $1,270,095[6.80 \%]$ & $1,312,235[9.80 \%]$ \\
\hline National Route & 723,106 & $775,997[6.80 \%]$ & $807,514[10.5 \%]$ \\
\hline State Route & 403,589 & $444,591[9.20 \%]$ & $472,737[14.6 \%]$ \\
\hline Local Road & 231,742 & $257,804[10.1 \%]$ & $280,576[17.4 \%]$ \\
\hline \multicolumn{4}{|c|}{ Net Present Cost (Not Including the Initial Construction Cost) (US\$/km) } \\
\hline Interstate & 199,240 & $285,632[43.4 \%]$ & $327,773[64.5 \%]$ \\
\hline National Route & 132,429 & $185,319[39.9 \%]$ & $216,837[63.7 \%]$ \\
\hline State Route & 108,251 & $149,252[37.9 \%]$ & $177,398[63.9 \%]$ \\
\hline Local Road & 84,072 & $110,135[31.0 \%]$ & $132,906[58.1 \%]$ \\
\hline
\end{tabular}

When applied to the entire pavement network in the U.S. we find that the implications of these costs are large. Projections are made for each of the models and from the median of the model ensemble for the sequential 30-year windows (2010, 2040, and 2070) in the dataset. The differences between these cases and the baseline scenario that assumes a stationarity climate represents our estimated impact from failing to adapt engineering practices to climate changes. The cost impacts are shown in Figure 3. The estimated costs across the U.S. based on RCP 4.5 are US\$13.6 in 2010, US\$19.0 in 2040, and US\$21.8 billion in 2070. Cost estimates for the same periods based on RCP 8.5 are US\$14.5, US\$26.3, and US\$35.8 billion, respectively. The variation in these costs are also large (as low as US\$8.8 billion in 2010 to as high as US $\$ 45.5$ billion in 2070) owing to the variability in model outcomes. To place the calculated impacts into perspective the cumulative baseline costs for the U.S. are approximately US $\$ 419$ billion. Thus, the impacts from temperature increases add approximately $3-9 \%$ to the cost to build and maintain the 
infrastructure over each 30-year period. A more comprehensive discussion of these variations is given in Supplementary Section 5 and a comparison to other similar estimates in the literature is given in Supplementary Section 6.

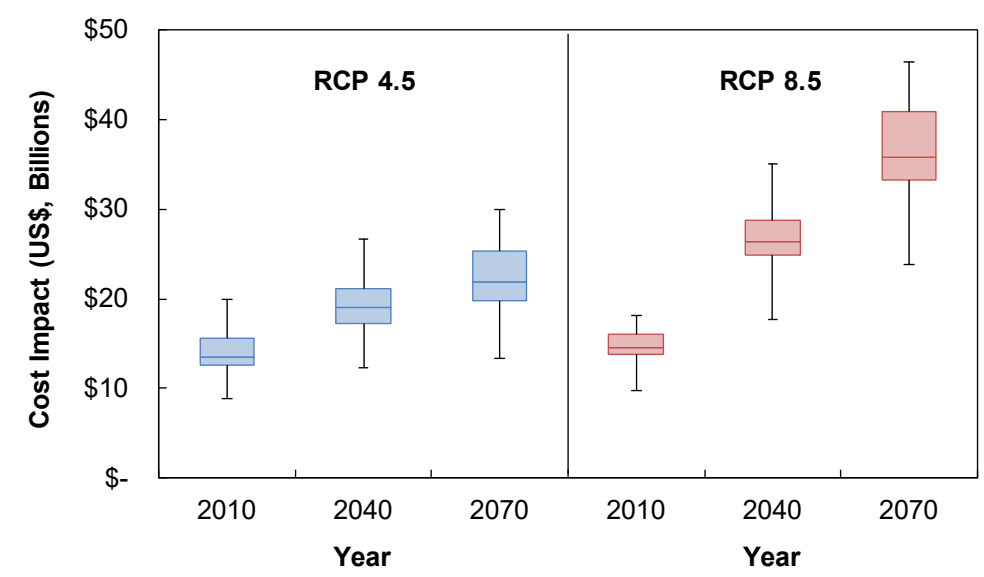

Figure 3. National cost impact from failing to adapt asphalt grade. Range of costs vary by year and RCP scenario considered. The projected costs are similar by RCP for the 2010-2040 period, but increases substantially by 2070-2100 period. The boxed areas enclose the $75^{\text {th }}$ and $25^{\text {th }}$ percentile range from the model ensemble. The horizontal line in these boxes is the median and the error bars show the maximum and minimum costs from the models in the ensemble.

Since maintenance and rehabilitation is the responsibility of each individual state, we also cumulate the data by each state individually and by region. Regionally, the Ohio Valley and Southeast are projected to be the most affected. Differences also exist with respect to the range of costs projected within a given scenario as well as the sensitivity to the future scenario. The Southeast, for example, is projected to have nearly identical results for both RCP 4.5 and RCP 8.5 scenarios, while the Upper Midwest, South, and Northeast show larger differences with respect to the future scenario (see Supplementary section 5). Another example, Delaware, has a large range in costs with the RCP 4.5 ensemble, while the projected impacts from the RCP 8.5 ensemble are almost identical for all models. At the state-level, Texas, California, Illinois, and Florida will experience the highest impacts (Supplementary Figure 5). These states maintain and manage large transportation networks so the results are not entirely surprising. Small states generally have less total cost impact than larger states, but on a per-kilometer basis smaller states like Maryland and Delaware show equal or greater effects than larger states (Supplementary Figure 6).

Our LCCA accounts for only a fraction of the total number of paved miles of the residential road network because details for these networks are not readily accessible in national data sources. However, the City of Phoenix, Arizona, is one network for which details are known. The city's network has more than $5,600 \mathrm{~km}$ of residential streets. By comparison the cumulative interstate, national route, and state route system in the entire state of Arizona is $9,900 \mathrm{~km}$. These 9,900 km of roads are maintained and rehabilitated with an annual budget of approximately US\$1.1 billion, whereas the City of Phoenix maintains its network on an annual budget of approximately US $\$ 57$ million. Even when accounting for the greater number of lanes in the state system, the State has about 8.5 times more financing per lane $\mathrm{km}$ than Phoenix. At the same time, the projected impact from climate change in Phoenix is substantial. The median RCP 8.5 scenario suggests a total cost 
impact for the period 2070-2100 of approximately US\$0.15 billion in Phoenix alone. During this same period, the projected impact for the entire state of Arizona is US\$0.53 billion.

We have detailed information on the length of residential streets in Phoenix, but do not have data on residential streets nationwide. To identify State's that may experience greater effects from the residential networks we use the relative proportion of local miles to other roadway types as a surrogate measure of the relative extent of the residential street network. Using this measure (see Supplementary Figure 7) suggests that some states (California in particular) may be facing a substantially higher potential impact from what is estimated here (see Supplementary Section 5).

In terms of both performance and cost, a failure to update engineering standards of practice and adapt to climate change may leave the pavement infrastructure in the U.S. at risk. Based on the analysis here, we expect that the impacts will be greatest in geographically larger states, central and southeastern regions and local municipalities. The results of this analysis and comparisons between it and projections of mean air temperature rise across the US ${ }^{29,30}$ show that the impacts of climate change induced temperature rise cannot be uniquely related to the absolute value of air temperature or the change of this temperature in the future. The key contributors to this risk are: 1) the increase local in air temperature and year-to-year variation; 2) the geospatial location (notably the latitude), 3) the current engineering practices of the pavements inclusive of the current reliability of the asphalt grade; and 4) the density of the road network across roadway types. This study highlights that in given the temporal scale with which roadways are engineered to perform, in the future, it may be important that engineering practice incorporate up to date climate records and/or incorporate future climate projections to mitigate economic impact.

\section{REFERENCES}

1. National Research Council Committee on Climate Change (NRC) (2008). Potential Impacts of Climate Change on US Transportation. National Research Council (US). Division on Earth, \& Life Studies Transportation Research Board, Washington, D.C.

2. Meyer, M., M. Flood, J. Keller, J. Lennon, G. McVoy, C. Dorney, K. Leonard, R. Hyman, \& J. Smith (2014). Strategic Issues Facing Transportation, Volume 2: Climate Change, Extreme Weather Events, and the Highway System: Practioner's Guide and Research Report. NCHRP Report 750, National Cooperative Highway Research Program, Washington, D.C.

3. Anderson, H., C. Beck, K. Gade, \& S. Olmsted (2015). Extreme Weather Vulnerability Assessment. FHWA No. 0704-0188.FHWA, Arizona Department of Transportation, Phoenix, AZ.

4. Cambridge Systematics, Inc. (2015). Central Texas Extreme Weather and Climate Change Vulnerability Assessment of Regional Transportation Infrastructure. FHWA No. 0704-0188. Capital Area Metropolitan Planning Organization, Austin TX.

5. Koetse, M.J. \& P. Rietveld (2009). The Impact of Climate Change and Weather on Transport: An Overview of Empirical Findings. Transportation Research Part D: Transport and Environment, 14(3), 205-221.doi: 10.1016/j.trd.2008.12.004

6. Rosenzweig, C., W.D. Solecki, S.A. Hammer, \& S. Mehrotra, (Eds.). (2011). Climate Change and Cities: First Assessment Report of the Urban Climate Change Research Network. Cambridge University Press. Cambridge, UK.

7. Huang, Y.H. (1993). Pavement Analysis and Design. Prentice Hall, Upper Saddle River, NJ. 
8. Yoder, E.J., \& M.W. Witczak (1975). Principles of Pavement Design. John Wiley \& Sons, New York, NY.

9. United States Department of Transportation (USDOT) (2015). Transportation in the United States. Bureau of Transportation Statistics Washington, DC.

10. United States Department of Transportation (USDOT) (2015). US. Beyond Traffic 2045: Trends and Choices. US Department of Transportation, Washington, DC.

11. American Society of Civil Engineers (ASCE) (2013). 2013 Report Card for Americas Infrastructure. Online. <http://www.infrastructurereportcard.org/>. Accessed January 2017.

12. Melillo, J.M., R. Terese, \& G.W. Yohe (Eds.) (2014). Climate Change Impacts in the United States: The Third National Climate Assessment. U.S. Global Change Research Program, 841 pp. doi:10.7930/J0Z31WJ2.

13. Knutti R \& J. Sedlacek (2013). Robustness and Uncertainties in the New CMIP5 Climate Model Projections. Nature Climate Change, 3, 369-373.

14. Mearns. L., R. Arritt, S. Biner, M.S. Bukovsky, S. McGinnis, S. Sain, D. Caya, J. Correia, D. Flory, W. Gutowski, E.S. Takle, R. Jones, R. Leung, W. Moufouma-Okia, L. McDaniel, A. M.B. Nunes, Y. Qian, J. Roads, L. Sload, \& M. Snyder (2012). The North American Regional Climate Change Assessment Program: Overview of Phase I Results. Bulletin of American Meteorology Society, 93, 1337-1362. doi: 10.1175/BAMS-D-11-00223.1.

15. Woldemeskel, F.M., A. Sharma, B. Sivakumar, \& R. Mehrotra (2016). Quantification of Precipitation and Temperature Uncertainties Simulated by CMIP3 and CMIP5 Models, Journal of Geophysical Research: Atmospheres, 121(1), 3-17. doi: 10.1002/2015JD023719

16. Wuebbles, D., G. Meehl, K. Hayhoe, T.R. Karl, K. Kunkel, B. Santer, M. Wehner, B. Colle, E.M. Fischer, R. Fu, A. Goodman, E. Janssen, V. Kharin, H. Lee, W. Li, L.N. Long, S.C. Olsen, Z. Pan, A. Seth, J. Sheffield, \& L. Sun (2014). CMIP5 Climate Model Analysis: Climate Extremes in the United States, Bulletin of the American Meteorology Society, 95, 571-583, doi: 10.1175/BAMS-D-12-00172.1

17. United States Department of Transportation (USDOT) (2016). National Transportation Statistics. Bureau of Transportation Statistics, Washington, DC. Online $<$ http://www.rita.dot. gov/bts/sites/rita.dot.gov.bts/files/publications/national transportation_statistics/index.html $>$. Accessed March 2016.

18. Chinowsky, P. \& C. Arndt . Climate Change and Roads: A Dynamic Stressor-Response Model. Review of the Development Economics, 16(3), pp. 448-462. doi: 10.1111/j.14679361.2012. 00673.x

19. Chinowsky, P.S., J.C. Price, \& J.E. Neumann (2013). Assessment of Climate Change Adaptation Costs for the US Road Network. Global Environmental Change, 23(4), 764-773. doi: 10.1061/9780784413326.

20. Daniel, J.S, J.M. Jacobs, E. Douglas, R.B. Mallick, \& K. Hayhoe (2014). Impact of Climate Change on Pavement Performance: Preliminary Lessons Learned through the Infrastructure and Climate Network (ICNet), In International Symposium of Climatic Effects on Pavement and Geotechnical Infrastructure 2013, Fairbanks AK. doi: 10.1061/9780784413326

21. Fletcher, C.G., L. Matthews, J. Andrey, \& A. Saunders (2016). Projected Changes in MidTwenty-First-Century Extreme Maximum Pavement Temperature in Canada. Journal of Applied Meteorology and Climatology, 55(4), 961-974. doi: 10.1175/JAMC-D-15-0232.1

22. Harvey, M., P. Whetton, K.L. McInnes, B. Cechet, J.L. McGregor, K. Nguyen, N. Houghton, C. Lester, E. Styles, N. Michael, \& T. Martin (2004). Impact of Climate Change on Road 
Infrastructure. Austroads Report No. AP-R243/04. Austroads and the Bureau of Transport and Regional Economics, Sydney.

23. Meagher, W., J.S. Daniel, J. Jacobs, \& E. Linder (2012). Method for Evaluating Implications of Climate Change for Design and Performance of Flexible Pavements. Transportation Research Record: Journal of the Transportation Board, 2305, 111-120. doi: 10.3141/2305-12

24. Mills, B.N., S.L. Tighe, J. Andrey, J.T. Smith, \& K. Huen (2009). Climate Change Implications for Flexible Pavement Design and Performance in Southern Canada, Journal of Transportation Engineering 135(10), 773-782. doi: 10.1061/(ASCE)0733-947X

25. Mndawe, M.B., J. Ndambuki, \& W.K. Kupolati (2013). Revision of the Macro Climatic Regions of Southern Africa. OIDA International Journal of Sustainable Development, 6(1) 3744.

26. Schweikert, A., P. Chinowsky, S. Espinet, \& M. Tarbert (2014). Climate Change and Infrastructure Impacts: Comparing the Impact on Roads in Ten Countries through 2100. Procedia Engineering, 78, 306-316. doi: 10.1016/j.proeng.2014.07.072

27. Viola, F. \& C. Celauro (2015). Effect of Climate Change on Asphalt Binder Selection for Road Construction in Italy. Transportation Research Part D: Transport and Environment, 37, 40-47. doi: $10.1016 /$ j.trd.2015.04.012

28. Asphalt Institute (2003). Superpave Performance Graded Asphalt Binder Specifications and Testing, Superpave Series No. 1 (SP-1). Asphalt Institute, Lexington, KY.

29. Maurer, E.P., L. Brekke, T. Pruitt, \& P.B. Duffy (2007). Fine-Resolution Climate Projections Enhance Regional Climate Change Impact Studies, Eos Transactions, American Geophysical Union, 88(47), 504. doi: 10.1371/journal.pone.0071297

30. Kunkel, K.E., X.Z. Liang, \& J. Zhu (2010). Regional Climate Model Projections and Uncertainties of US Summer Heat Waves. Journal of Climate, 23(16), 4447-4458.doi: 10.1175/2010JCLI3349.1

\section{CORRESPONDENCE}

Correspondence and requests for materials should be addressed to B. Shane Underwood at 919515-8632, shane.underwood@ncsu.edu, or 418 Mann Hall, North Carolina State University, Raleigh, NC 27695-7905.

\section{ACKNOWLEDGEMENTS}

We acknowledge the World Climate Research Program's Working Group on Coupled Modeling, which is responsible for CMIP, and we thank the climate modeling groups (listed in Supplementary Table 1) for producing and making available their model output. For CMIP the U.S. Department of Energy's Program for Climate Model Diagnosis and Intercomparison provides coordinating support and led development of software infrastructure in partnership with the Global Organization for Earth System Science Portals. We would also like to acknowledge the Climate Assessment for the Southwest (CLIMAS) at the University of Arizona provided support to Zack Guido.

\section{Author Contributions}

B.S.U designed the study, identified the data sources, created the scripts to analyze the climate data, and developed the structure of the paper in collaboration with Z.G. and P.G., Z.G. provided inputs on climate modeling and ensemble interpretation and review of the manuscript, P.G. reviewed the manuscript and discussed interpretation of the data at length, Y.F. assisted in downloading, cataloging, and running the climate scripts. All authors contributed equally to developing the ideas in this paper. 
ADDitional INFORMATION

Methods and Supplementary information is available.

COMPETING FINANCIAL INTERESTS

The authors declare no competing financial interests. 


\section{METHODS}

\section{Climate Data}

Two climate databases were used in this study; 1) the United States Historical Climatology Network (USHCN) and 2) a global climate model (GCM) ensemble of 19 climate models each under Representative Concentration Pathway (RCP) 8.5 and 4.5. In both cases we use the 19661995 climate record as the comparative reference because this is the current basis of binder selection in the United States. The objective in this analysis is to quantify the impacts from continuing to adhere to a static database, which means comparing future year effects to the current state of the practice and the condition that will exist if engineers continue to adhere to this practice.

\section{USHCN Data Processing}

We accessed the USHCN database through the U.S. Department of Energy portal and downloaded the daily maximum and minimum temperatures (http://cdiac.ornl.gov/ftp/ushen_daily/). We choose this database to determine the impact of present day temperatures on PG because although there are fewer weather stations in the database than others, they are quality controlled so that each station has minimal missing data and data records are available covering the period time of interest. Only those weather stations with complete daily temperature data from January 1, 1966 through December 31, 2014 are considered. In total, 799 weather stations met this criterion and their location are shown in Figure 1 of the manuscript. For each station, the data for the years 19661995 as well as the most recent 30-year period available (1985-2014) are extracted from the files using custom MATLAB scripts.

\section{GCM Data Processing}

We selected GCM's for the ensemble from those models that participated in the Coupled Model Intercomparison Project 5 (CMIP5), had daily maximum and minimum temperature data for RCP 8.5 and RCP 4.5 scenarios, and were available in $1 / 8^{\circ}$ resolution ${ }^{29,31,32}$. The data were downloaded from the archives of the Climate Analytics Group (ftp://gdo-dcp.ucllnl.org/pub/dcp/archive/ cmip5/bcca). For analysis, projections are grouped by 30 -year periods. These periods begin in the first year of a decade (2010, 2040, and 2070) and are staged in 30-year increments. Results presented as "2010" are based on the temperature projections for the period from January 1, 2010 to December 31, 2039; data given as "2040" are based on data for 2040-2069, and so forth. For statistical analysis purposes, and to most easily compare current and future scenarios, the downscaled data is geospatially interpolated to the coordinates of the Superpave weather stations ${ }^{33}$. This extraction and interpolation is performed using custom MATLAB scripts.

\section{Superpave Method of Asphalt Cement Specification}

To determine the asphalt grade, we follow the standard performance grade (PG) method. Equations (1) and (2) are then used to estimate the minimum pavement and seven consecutive day average maximum pavement temperatures, respectively ${ }^{33}$. These temperatures are used in the Superpave method because they relate to either thermal cracking (low temperature) or rutting (high temperature).

$$
\begin{aligned}
& T_{\text {pav low }}=7.191+0.72\left(T_{\text {air }, \text { low }}-z \times \sigma_{\text {air }, \text { low }}\right)-0.004 \text { Lat }^{2}-z\left(4.4+0.52\left(\sigma_{\text {air }, \text { low }}\right)^{2}\right)^{0.5} \\
& T_{\text {pav }, \text { igh }}=\left(\left(T_{\text {air }, \text { high }}+z \times \sigma_{\text {air }, \text { high }}\right)-0.00618 L a t^{2}+0.2289 L a t+42.2\right)(0.9545)-17.78
\end{aligned}
$$


Where, $T_{\text {air }, \text { low }}=$ minimum average air temperature $\left({ }^{\circ} \mathrm{C}\right)$, Lat $=$ latitude (decimal degrees), $z=$ standard normal deviate $(50 \%$ reliability $\mathrm{z}=0,98 \%$ reliability $\mathrm{z}=2.055)$, $\sigma_{\text {air }, \text { low }}=$ standard deviation of minimum air temperature $\left({ }^{\circ} \mathrm{C}\right)$, $\sigma_{\text {air }}$ high $=$ standard deviation of 7 consecutive day hot temperature $\left({ }^{\circ} \mathrm{C}\right), T_{p a v, l o w}=$ pavement hot temperature $\left({ }^{\circ} \mathrm{C}\right)$, and $T_{\text {air }, \text { high }}=7$ consecutive day high temperature grade $\left({ }^{\circ} \mathrm{C}\right)$. Latitude and longitude for GCM ensemble are the same as the Superpave weather stations and for the USHCN database they are extracted directly from the datafile. The daily maximum and minimum air temperatures at each location are extracted from the downloaded databases, arranged by year, and processed to determine the minimum air temperature and the highest seven consecutive day average maximum air temperature for each year in the record. Then, the average and standard deviation for these annual values are calculated.

The process accounts for exceptionally hot summers and cold winters by embedding statistical uncertainty into Equations (1) and (2). This is conventionally termed reliability, and is mathematically defined as the probability (expressed as a percentage) that the temperatures will not be exceeded in any given year. When the average of the annual air temperatures is used in these calculations, there is a $50 \%$ probability that a given year will exceed the average, and thus grades that are based on the averages are referred to as the asphalt grade at $50 \%$ reliability. Generally, engineers consider it to be too risky to use this grade and by convention choose a temperature that yields a $98 \%$ reliability.

The final step adjusts the calculated $50 \%$ or $98 \%$ reliability pavement temperatures to standard, six-degree temperature increments. For the high temperature grade, these are: 82, 76, 70, 64, 58, 52 , and $46^{\circ} \mathrm{C}$ and for the low temperature they are $-46,-40,-34,-28,-22,-16$, and $-10^{\circ} \mathrm{C}$. This rounding process increases the true reliability of the given asphalt grade, but by convention it is still referred to as either the $50 \%$ or $98 \%$ reliability grade. Equations (1) and (2) can be rearranged to determine the true low temperature $\left(R_{L T}\right)$ and high temperature $\left(R_{H T}\right)$ reliability of a selected grade, Equations (3) and (4).

$$
\begin{aligned}
& R_{L T}=0.5\left[1+\operatorname{erf}\left(\frac{7.191-L T-0.004 \text { Lat }^{2}+0.72 T_{\text {air }, \text { low }}}{\left(0.72 \sigma_{\text {air }}+\left(4.4+0.52\left(\sigma_{\text {air }}\right)^{2}\right)^{0.5}\right) \sqrt{2}}\right)\right] \times 100 \\
& R_{H T}=0.5\left[1+\operatorname{erf}\left(\frac{\frac{H T+17.78}{0.9545}+0.00618 \text { Lat }^{2}-0.2289 \text { Lat }-42.2-T_{\text {air }, \text { high }}}{\sigma_{\text {air }} \sqrt{2}}\right)\right] \times 100
\end{aligned}
$$

Where, $L T$ and $H T=$ low and high temperature grades against which the reliability is evaluated.

For the USHCN database we use Equations (1) and (2) to calculate the standard grade from both the 1966-1995 and 1985-2014 temperature record. We compare these results to identify the stations where the two databases yield different grades. For each model in the GCM ensemble and for each time window in the study $(2010,2040$, and 2070), we apply the method above to calculate the projected $98 \%$ pavement temperature for each time period and for each location. We then 
calculate the difference between these temperatures when using the 1966-1995 climate record and from the median of the GCM ensemble. These temperature differences are graphically depicted for the RCP 8.5 scenario in the manuscript (Figure 2) and for RCP 4.5 scenario in Supplementary Figure 1. The outcomes from Equations (1) and (2) are also used to compute the standard grade (i.e., the grade in the standard temperature increments). This grade is compared with the currently specified grade and the results are shown in Supplementary Figure 2. Finally, we substitute the averages and standard deviations for the high and low temperatures into Equations (3) and (4) along with the current asphalt grade to estimate the future true reliability. We present statistical analysis of this true reliability in Supplementary Figure 4.

\section{Uncertainty Analysis of Projected Impacts}

We evaluate the impacts by state, region (defined using the National Climatic Data Center regions, Supplementary Figure 3), and nation. The variability of the climate models is examined across regions by using the Beta Function, Equation (5). Characterization of this function reveals that the ensembles result in a skewed distribution of impacts, which we use to justify selecting the median as the central tendency measure of the ensemble. The median value is estimated by finding the parameters of the beta function $(\alpha, \beta, a$, and $c)$ using the Pearson method ${ }^{34}$. Detailed descriptions of the findings by region are presented in the manuscript and in Supplementary Section 3.

$P=\frac{\Gamma(\alpha+\beta)}{\Gamma(\alpha) \Gamma(\beta)}\left(\frac{x-a}{c-a}\right)^{\alpha-1}\left(1-\frac{x-a}{c-a}\right)^{\beta-1} \times 100$

Where, $P=$ cumulative probability of given true reliability, $x, \alpha$ and $\beta=$ beta distribution parameters, $a$ and $c=$ the maximum and minimum values of the distribution function, and $\Gamma()=$ gamma function.

\section{Impact Assessment}

To estimate the cost impacts, we perform four steps; 1) we use the nationally calibrated Pavement Design ME model to calculate performance reductions resulting from the temperature-induced shortfalls in grades, 2) we estimate changes to the construction, maintenance, and rehabilitation activities brought on by reduced performance and the life cycle costs of these scenarios, 3) we coordinate roadway lengths to the nearest corresponding weather station, and 4) we calculate the increased costs using life cycle cost analysis (LCCA).

\section{Pavement ME Design Model}

The American Association of State Highway and Transportation Officials (AASHTO) Pavement Design ME simulation tool is used to estimate the performance impacts from using an incorrect asphalt grade. We elected to use Pavement Design ME because it is the only pavement analysis and design tool that has undergone extensive national calibration and one of the only that can directly consider asphalt grade in the performance prediction process. This tool explicitly considers the individual and interactive effects of local temperature, traffic, material (including the PG grade used), soil conditions, and the pavement structural configuration of the roadway types. To integrate these factors, Pavement Design ME uses a complex assemblage of models and routines that link the response of a pavement under trafficking to cracking, rutting, and ride quality changes over the lifetime of the pavement structure (approximately 20 years). 
We simulate the performance of four roadway types (interstate, national route, state route, and local roads) in cold, moderate, and warm climate zones (Minneapolis, Minnesota; Raleigh, North Carolina; and Miami, Florida). The pavements are simulated so that the correct asphalt has a service life of 18-22 years. The relevant inputs for each of the simulations are given in Supplementary Table 3 . For variables not explicitly given in this table (asphalt content, air void content, thermodynamic properties, etc.) the default parameters of the simulation tool are used. The climate records for each of these cities are available within the support files for the simulation tool and the soil properties are found using the soil survey tool available at (http://nchrp923b.lab.asu.edu/) $)^{35}$. For climate and roadway type, the simulations are first performed by inputting the correct asphalt grade for the current climate. Then subsequent simulations are carried out with a grade that is either one or two standard increments below the current grade. We elected to follow this approach and use the predicted performance under current climate and current asphalt grade as the reference condition for performance estimations because of inconsistencies in using the GCM predicted climate input in the Pavement Design ME model. The pavement model uses hourly temperature values whereas the GCMs provide only daily maximum and minimum temperatures. Projecting the future hourly temperature variations and analyzing pavement performance under future climate grades would introduce additional uncertainty.

The basic prediction process followed in Pavement Design ME to predict fatigue cracking and rutting are given in Supplementary Section 4 and even more detailed descriptions of the models can be found elsewhere ${ }^{36-42}$. For our analysis, we focused on the cracking and rutting distresses because the predicted values have greater certainty than others and because we were most interested in the structural performance of the pavements. Thermal cracking is also predicted from the Pavement Design ME model and is a distress that is directly related to climate. However, we do not consider thermal cracking effects in our analysis because as the data in Figure 2 in the manuscript and Supplementary Figure 1 demonstrates, future climate change suggests a warming of the yearly cold temperature, which would result in less future thermal cracking. Other relevant performance measures do exist (raveling and pothole formation for example), and we recognize that future climate changes will affect the mechanisms that cause these distresses. For example, higher temperatures will result in faster oxidation of the asphalt, which can embrittle the material and make it more likely to ravel. However, the science describing the mechanics of these distresses has not produced comprehensive mechanistically based models capable of reliably predicting the initiation and growth of these distresses. Empirical models do exist, but these may combine multiple confounding factors into single variables (for example a temperature variable in the empirical model may implicitly assume an asphalt type that is associated with that temperature), which makes it difficult to consider the effects of asphalt changes on the resulting performance.

For the structural inputs to the model we recognize that pavement design methodologies can vary substantially between and within states. Even more, agencies do not always keep accurate records of the in-place designs or the standards that they follow. Although the specific designs for every roadway are difficult to identify, most pavement designs in the U.S. use a common paradigm: asphalt concrete is placed on a supporting layer of unbound and compacted granular base, which then rests on compacted native soil. The thickness of the pavement layers is a function of loading severity (both in terms of actual load levels and the number of repetitions). Loading severity strongly correlates with the roadway types: interstate (most severe loading), national route, state 
route, or local road (least severe loading). In this analysis, we consider this effect by creating four different representative pavement structures for the simulations. The thickness of these representative pavement types varies as shown in Supplementary Table 3, with the thinner asphalt concrete pavements used for the roads with fewer trucks.

We assume that structural failure of a pavement occurs when either the fatigue cracking reaches $20 \%$ of the total lane area ${ }^{36}$ or total pavement rutting is equal to $12.5 \mathrm{~mm}^{43}$. We estimate the loss of performance from an incorrect asphalt by comparing the time to failure (to the half year) when the correct asphalt grade is used to the time to failure when an incorrect asphalt grade is used, Equation (6).

$$
P L=\frac{t_{\text {failure-baseline }}-t_{\text {failure-_grade }}}{t_{\text {failure-baseline }}} \times 100
$$

Where, $P L=$ performance loss, $t_{\text {failure-baseline }}=$ years to failure when the correct asphalt grade is used, $t_{\text {failure- } \Delta \text { grade }}=$ years to failure when the asphalt grade used is wrong by either one or two increments.

\section{Maintenance and Rehabilitation Planning}

To conduct the LCCA we develop a 30-year life cycle plan involving the timing of maintenance and rehabilitation activities. We start by developing a schedule for the case where the correct asphalt is used (the reference schedule). The basis of this schedule is our own engineering experience, the guidelines for Indiana and New York ${ }^{44,45}$, and national guidance ${ }^{46,47}$. We then develop schedules for the case where the asphalt is wrong by one or two grades by modifying the timing of the individual activities in the reference schedule by the same amount as the performance loss. For example, we estimated that the $P L$ of an interstate pavement with an incorrect asphalt grade was $10 \%$. In the reference schedule, a major rehabilitation will occur at year 16, but based on the $10 \%$ loss in performance this activity is now expected to occur in year $14.4(16 \times 0.9=$ 14.4), which we round in our final adjusted schedule so that it takes place in year 14. Explicit justification for using this linear scaling method is given in Supplementary Section 4. $P L$ 's change by roadway type and grade deficiency and so the timing varies accordingly. The performance losses are given in Supplementary Section 4. Supplementary Table 2 lists the activities for each of the scenarios sequentially where the numbers given in the table for each activity correspond to the year in which the activities occur. The Correct Grade Schedule is the expected strategy when the correct asphalt grade is used, whereas -1 and -2 Standard Grade Schedules are when the asphalt grades are wrong one and two grades, respectively.

\section{Coordinating Roadways to Weather Stations}

We identify the roadways associated with each weather station by using the built-in functionality of ArcMap (Version 10.3) to draw Thiessen polygons around the 5,417 weather stations in the database. These polygons define the nearest geospatial areas to each weather station. We then extract roadway segments from the National Highway Performance Network (NHPN) database, which contains details on all interstates, national routes, state routes, and paved local roads in the United States $^{48}$. Using Geographical Information Software, we then calculate the total length of each type of roadway contained within each weather station polygon.

\section{Life Cycle Cost Analysis}

We conduct LCCA analysis based on the maintenance and rehabilitation schedules in Supplementary Table 2. The unit of the analysis is a one-kilometer segment of the roadway type 
in question. The number of lanes assumed for each roadway type is based on national averages: interstate and national routes are four lanes wide, state routes are three lanes wide, and local routes have two lanes ${ }^{17}$. Quantities of materials are estimated assuming that each lane is $3.7 \mathrm{~m}$ wide. The costs associated with each activity are based on values used by the North Carolina and Arizona Departments of Transportation. Both states have extensive transportation networks with multiple suppliers so they provide an overall representative indication of national costs. All costs are returned to the base year and summed according to Equation (7).

$$
N P V=I C+\sum_{j=1}^{N} R_{j}\left[\frac{1}{\left(1+i^{\prime}\right)^{n_{j}}}\right]-\text { Salvage }\left[\frac{1}{\left(1+i^{\prime}\right)^{N}}\right]
$$

Where, $N P V=$ net present value, $I C=$ initial cost, $R_{j}=$ rehabilitation expenditure (single cost expenditure), Salvage $=$ the salvage value at the end of the analysis period, $i^{\prime}=$ the discount rate, assumed $4 \%{ }^{47}$, and $n_{j}=$ year of expenditure. The salvage value is calculated by multiplying the construction cost by the proportion of remaining life.

We estimate the total $N P V$ associated with each weather station by first determining which maintenance and rehabilitation schedule to follow. We then multiply the number of lane kilometers for each type of roadway by the $N P V$ for the appropriate maintenance and rehabilitation schedule (see Table 1). So, for example a weather station with 10 kilometers of interstate would have a total estimated $N P V$ of US $\$ 11,837,020$ when the correct asphalt was used, while the same station would have a $N P V$ of US $\$ 12,700,950$ when the asphalt was wrong by one grade. The impact is quantified by the difference between the future scenario costs and the costs when all roadways have the correct asphalt grade. We cumulate the results for all models and weather stations, and also disaggregate them by state and region (see Figure 3 in the manuscript and Supplementary Figure 5 ). We estimate the regional and state costs on a per lane kilometer cost by dividing the costs by the lane kilometers (Supplementary Figure 6). For the ensemble of models, we calculate the median, maximum, minimum, and $75^{\text {th }}\left(N P V^{7 \text { sth percentile }}\right)$ and $25^{\text {th }}\left(N P V^{25 t h ~ p e r c e n t i l e ~}\right)$ percentiles. For analysis by state and region, we identify outlying model predictions using the interquartile range as shown in Equation $(8)^{49}$.

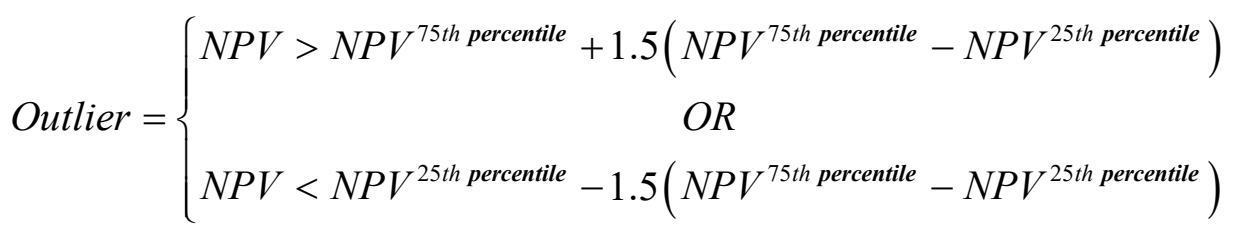

\section{Data Availability}

The authors declare that the datasets used for this study are available from http://cdiac.ornl.gov/ftp/ushen_daily/ and from ftp://gdo-dep.ucllnl.org/pub/dcp/archive/ cmip5/bcca. Also, data analysis files, and Matlab and Labview scripts supporting the asphalt binder grade determination and economic analysis are available from the corresponding author [BSU] upon request.

\section{References}

31. Climate Analytics Group (2015). Downscaled CMIP3 and CMIP5 Climate and Hydrology Projections. U.S. Department of the Interior, Bureau of Reclamation, Technical Service 
Center, Denver, CO. Online <ftp://gdo-dcp.ucllnl.org/pub/dcp/archive/cmip5/bcca $>$ Accessed September 2015.

32. Reclamation, 2013. Downscaled CMIP3 and CMIP5 Climate Projections: Release of Downscaled CMIP5 Climate Projections, Comparison with Preceding Information, and Summary of User Needs. U.S. Department of the Interior, Bureau of Reclamation, Technical Service Center, Denver, CO, 116. Online <http://gdo-dcp.ucllnl.org/downscaled_cmip projections/techmemo/downscaled_climate.pdf $>$ Accessed September 2015.

33. Huber, G.A. (1994). Weather Database for the Superpave Mix Design System, SHRP-A-648A, Strategic Highway Research Program, Washington, DC.

34. Johnson, N.L. \& S. Kotz (1970). Continuous Univariate Distributions: Chapter 24 - Beta Distributions, Houghton Mifflin Company, Boston MA.

35. Zapata, C.E, \& C.E. Cary (2012). Integrating the National Database of Subgrade Soil-Water Characteristic Curves and Soil Index Properties With the MEPDG. Final Report for NCHRP 9-23b. National Cooperative Highway Research Program, Washington, DC.

36. Applied Research Associates (ARA) (2004). Guide for Mechanistic-Empirical Design of New and Rehabilitated Pavement Structures. Final Report. NCHRP 1-37A. National Cooperative Highway Research Program, National Research Council, Washington, DC.

37. Darter,M.I., L.T. Glover, H. Von Quintus, B.B. Bhattacharya, \& J. Mallela (2014). Calibration and Implementation of the AASHTO Mechanistic-Empirical Pavement Design Guide in Arizona, FHWA-AZ-14-606. FHWA, Arizona Department of Transportation, Phoenix AZ.

38. Heitzman, M., D. Timm, E.S. Tackle, D.E. Herzmann, \& D.D. Traux (2011). Developing MEPDG Climate Data Input Files for Mississippi, FHWA/MS-DOT-RD-11-232.FHWA, Mississippi Department of Transportation, Jackson, MS.

39. Pierce, L.M. \& G. McGovern (2014). Implementation of the AASHTO Mechanistic-Empirical Pavement Design Guide and Software. Project 20-05, Topic 44-06, National Cooperative Highway Research Program, NCHRP, Washington, D.C.

40. Smith, B. \& H. Nair (2015). Development of Local Calibration Factors and Design Criteria Values for Mechanistic-Empirical Pavement Design, FHWA/VCTIR 16-R1.FHWA, Virginia Center of Transportation, Richmond VA.

41. VonQuintus, H.L. \& J.S. Moulthrop (2007). Mechanistic-Empirical Pavement Design Guide Flexible Pavement Performance Prediction Models for Montana, Volume III: Field Guide Calibration and Users Guide for the Mechanistic-Empirical Pavement Design Guide, FHWA/MT-07-008/8158-3.FHWA, Montana Department of Transportation, Helena, MT.

42. Witczak, M.W., C.E. Zapata, \& W.N. Houston (2006). Models Incorporated into the Current Enhanced Integrated Climatic Model, Final Report, National Cooperative Highway Research Program, Washington, DC.

43. Fwa, T.F., H.R. Pasindu, \& G.P. Ong (2011). Critical Rut Depth for Pavement Maintenance Based on Vehicle Skidding and Hydroplaning Consideration, Journal of Transportation Engineering, 138(4), 423-429. doi: 10.1061/(ASCE)TE.1943-5436.0000336.

44. Lamptey, G., M.Z. Ahmad, S. Labi, \& C.S. Kumares (2005). Life Cycle Cost Analysis for INDOT Pavement Design Procedures, FHWA/IN/JTRP-2004/28. Indiana Department of Transportation, Indianapolis, IN.

45. New York Department of Transportation (NYDOT) (2002). Comprehensive Pavement Design Manual: Chapter 5 Rehabilitation. NYDOT Design Division and Technical Service Division. Albany, NY. 
46. Santero, N. (2010). Life Cycle Assessment of Pavements: A Critical Review of Existing Literature and Research, Lawrence Berkeley National Laboratory, Online < https://www.osti.gov/scitech/servlets/purl/985846>. Accessed October 2016

47. Walls, J. \& M.R. Smith (1998). Life Cycle Cost Analysis in Pavement Design - Interim Technical Bulletin, FHWA-SA98-079, Federal Highway Administration, Washington, DC.

48. National Highway Planning Network (NHPN) (2015). National Highway Planning Network Tools - Processes - Planning Online <http://www.fhwa.dot.gov/planning/processes/tools/ nhpn/>. Accessed March 2015.

49. NIST/SEMATECH (2012). e-Handbook of Statistical Methods, National Institute of Standards and Technology. Online. <http://www.itl.nist.gov/div898/handbook/> Accessed June 2017. 


\section{Increased Costs to US Pavement Infrastructure from Future Temperature Rise}

B. Shane Underwood ${ }^{a^{*}}$, Ph.D., Zack Guido ${ }^{\mathrm{b}}$, Ph.D., Padmini Gudipudi, Ph.D. ${ }^{\mathrm{c}}$, Yarden Feinberg $^{\mathrm{d}}$

a Assistant Professor, Arizona State University, School of Sustainable Engineering and the Built Environment, PO Box 875306, Tempe, AZ 85287-5306 USA Shane.Underwood@ncsu.edu, Phone: 1919515 8632, Fax: 19195157908

${ }^{b}$ Research Scientist, Institute of the Environment, University of Arizona, Tucson, AZ 85721 USA

${ }^{c}$ Postdoctoral Scholar, Arizona State University, School of Sustainable Engineering and the Built Environment, PO Box 875306, Tempe, AZ 85287-5306 USA pgudipud@asu.edu

${ }^{d}$ Undergraduate Researcher, Arizona State University, School of Sustainable Engineering and the Built Environment, PO Box 875306, Tempe, AZ 85287-5306 USA

\section{NEEd AND CONTRIBUTION}

To identify and quantify the impacts of climate changes on transportation infrastructure we utilize data from the United States Historical Climate Network (USHCN), the Superpave weather station network, and the CMIP5 climate projection project. The basis of this analysis is that current protocols guide engineers to use an outdated, static temperature dataset to determine material grades, and therefore, their costs. We thus identify how past, current, and future climate trends may affect the asphalt cement used in the extensive U.S. roadway network and the resultant economic costs of failing to adapt engineering practices to a non-stationary climate record.

This issue has been studied by others using techniques like the ones we have adopted, but we believe that these studies have one or more factors that limits the applicability of their findings. Some have focused heavily on climate projections but made correlations to infrastructure performance without supportive engineering analysis ${ }^{1}$, others have failed to recognize the totality of local factors (materials, construction practices, and climate) that occur when delivering infrastructure ${ }^{2-4}$, still others stopped short of linking potential engineering outputs to economic and social impacts 5,6 , or have been too narrowly scoped to provide a complete geospatial and temporal perspective ${ }^{7-11}$. In short, many of the assessments conducted to date have focused on the correlation between climatological stressors and the presence of infrastructure, but without consideration for the engineering processes of the in-place infrastructure. By failing to consider these factors analyses systematically bias findings to locations where climate change is projected to have the greatest change in temperature and/or precipitation, but not necessarily where those changes will have the greatest impact on the pavement infrastructure.

Chinowsky and $\mathrm{Arndt}^{2}$ provided one of the first (and only) nationally scoped estimates of climate impacts on pavements. They developed an economic dynamic-stressor model based on empirical performance impacts from precipitation and temperature to examine the issue of climate change and roads. These models reflect, but do not necessarily predict the precise impact of climate change on materials since the empirical functions are calibrated with real-world data where material choices are correlated to climate. Follow-up studies then used this framework to investigate the economic cost of projected climate change on paved and unpaved roads across the United States ${ }^{3}$. Climate projections were made across a 2.5 by 2.5 grid of the United States under a scenario of business as usual growth (approximating the CMIP3 AIB scenario) and under a scenario of 
substantial reductions consistent with the Kyoto protocols. The authors concluded that by 2050 the annual adaptation cost would be US\$785.0 million (in 2012 dollars) with the greatest impact in the Southeast and Midwest. A follow-up study applied to only the State of Colorado concluded that the benefits of adapting pavement strategies to climate change for that state could result in a US\$22 million annual savings by $2050^{4}$.

While impressive in scope, the authors had to rely on generalizations of regional or international performance experiences to generate these estimates. Such estimates are questionable though given the highly local nature of materials, design, and construction practices. For example, in the case of heat impacts, costs were estimated based on the published costs of materials from the Colorado Department of Transportation. The authors did not consider that these costs would change as market conditions change (i.e., as local and regional temperatures change, the demand for certain grades would change and hence costs would adjust) and that the costs chosen assumed that low temperature grades would remain the same even. However, winter temperatures are also projected to increase and thus both high and low temperature grades will change jointly. When both grades change the complexity in producing the asphalt is reduced greatly and thus it is likely that costs would be substantially lower than what was estimated. This overestimation is quite important since the major contributor to costs in their analysis was the increased asphalt prices that climate change would bring.

The authors did attempt to address increased maintenance activities using these empirical models. However, to create a workable analysis, they had to assume a linear degradation of performance, which does not accurately reflect the behaviors of pavements, which degrade at an increasing rate $^{12,13}$. Mallick et al. addressed network performance in a more comprehensive way by first developing a Systems Dynamics model for individual pavement performance based on a set of simulations. They then applied this model under constrained economics and uncertainty to propose a framework to incorporate climate change projections (expressed as a mean and standard deviation) into decision making on pavement network management. While they did apply their model to several urban pavement systems they stopped short of making economic projections ${ }^{14}$.

Viola and Celauro ${ }^{5}$ conducted an analysis for Italy. The authors analyzed historical and future climate projections in Italy and concluded that temperature rise occurring through 2033 would increase the required asphalt grade for $27 \%$ of the country by one standard increment. The future climate was projected based on linear extrapolation of the historical data trends. A similar study has also been conducted for urban areas in Canada using 10 models from the A2 scenario of the third phase of the Coupled Model Intercomparison Project (CMIP3) and found that 41\% of the cities would likely require a higher asphalt grade by mid-century ${ }^{6}$. Neither of these studies postulated on the nature of adaptation strategies or the cost impacts.

Researchers have also studied this issue at a finer, project level scale. Much of this work has focused on pavements in the New England region. In these cases, climate predictions were incorporated into the pavement design process and results were compared with design/analysis completed using the historical data. One study concluded that climate change predictions have a significant effect on pavement distresses specifically that the pavement life can decrease from 16 years to 4 years and maintenance cost may also increase by $100 \%{ }^{11}$ while another found that changes in cracking for secondary roads and interstate pavements was negligible but for other 
roadways that the cracking increased by between $4 \%$ and $16 \%$ after 20 years ${ }^{8}$. The loss of performance and associated changes in construction and maintenance have been documented elsewhere too ${ }^{7-9}$. Qiao et al. ${ }^{15}$ used a scenario in southern Virginia to estimate increases in total life cycle costs of $1-2 \%$ from climate change. The primary shortcoming in these project level assessments is a lack of national or even regional scope, thus it is difficult to identify from these simulations the relative impact of climate change across the country.

While a body of work has developed that suggests future climate changes will have an impact on the costs of transportation infrastructure, the review above identifies some key limitations. Efforts using the most accurate and reliable performance predictions, are either limited in geospatialtemporal scope, do not consider the cost implications of those performance differences, or focus on developing a framework for project level assessment instead of conducting an economic assessment. On the other hand, research that has produced national impact assessment have had to rely on more questionable performance predictions and scenarios that may not be accurate reflections of practice. A hybrid of these two approaches using a limited set of accurate performance predictions in conjunction with a simpler performance metric is used here to balance accuracy with a workable analysis.

National estimates of economic impact have all made assumptions that engineers would have information on climate change available and would make material selections to adequately compensate for heat rise. No estimates have been given that consider a scenario where engineers do not have perfect information and continue choosing strategies using a business as usual mindset. This aspect is quite important in estimating costs since it must be realized that the collection of institutions that design and construct the physical infrastructure of transportation networks are mature and have evolved gradually ${ }^{16-20}$. This gradual evolution is driven largely by the fact that their actions rely on embodied information gained through learning by trial and error. This evolutionary process yields a direction bias with respect to actions and processes that has been well documented in the literature ${ }^{21}$ and the sources therein . Standards, such as the ones that dictate the use of a 1966-1995 climate record for selecting the asphalt grade are an explicit expression of this bias.

Since the evolution of these standards occurs in the public domain, the drivers for change are often political, economic, social (as in public demand), and in some instances reactive to shock (as in when building requirements change after a high-profile collapse). Although the stressors that drive changes to these standards are largely social, their connection with the technical is apparent ${ }^{19,22,23}$. It happens though that in mature institutions, generalizing technological know-how across the organization is typically slow and expensive because although data and experiences are shared ${ }^{24,25}$, adoption often requires repetition of experiences on systems that can take a decade or more to show their response. So, with respect to long-term heat rise from climate change, we expect the issue of asphalt grade selection to go largely unnoticed by the public and to have relatively low priority politically. As such we surmise that it is unlikely that the institutions would naturally embed climate projections into asphalt selection and make appropriate decisions based on these outcomes. We therefore conduct our economic analysis based on a scenario where institutions engaged in the engineering and delivery of transportation infrastructure would continue operating under a policy of material selection based on an outdated climate record and the implicit assumption of stationarity. Also, in an important advancement in the area of cost estimation for pavements, we conduct our economic analysis for each individual model in both RCP 8.5 and RCP 
4.5 scenarios of our ensemble and present the results in terms of the statistical range (interquartile and maximum/minimum) of expected costs. It is noted that others have also performed an economic analysis using different scenarios, but only used a single model with different forcings ${ }^{3}$.

\section{ANALYSIS FOR FUtURe YeAR EFFECTS}

Figure 2 in the manuscript and Figure S1 show the projected pavement temperature increases at different time periods for RCP 8.5 and RCP 4.5 scenarios respectively. While these maps show that pavement temperatures will increase in the future, the increases may not necessarily result in changes in the required high temperature grade. A standard incremental change in the grade is also dependent upon the level of reliability that exists with the current grade. Consider two locations, in the first the $98 \%$ pavement high-temperature is $59^{\circ} \mathrm{C}$ and in the second it is $63^{\circ} \mathrm{C}$. At both locations, the engineer would specify a PG 64-XX asphalt. In this scenario, the true reliability of location one is greater than the true reliability of location two even though both have the same acceptable PG grade. The impact of these differences is that in the first location, the projected pavement temperature would have to increase by $6^{\circ} \mathrm{C}$ for the asphalt grade to change while at the second location a $2^{\circ} \mathrm{C}$ temperature increase would warrant an asphalt grade change.

Figure S2 presents the grade change that results from the pavement temperature shown in Figure 2 and Figure $\mathrm{S} 1$ for each of the three analysis periods considered here. It is seen that even in locations where a $0-1{ }^{\circ} \mathrm{C}$ temperature change is projected the required grade may change. It is also seen that in the scenarios studied a maximum of two grade changes are projected, e.g., the models project that future reliance on current asphalt grades will result in specifications that are wrong by one or two grades. Comparing Figure S2, especially parts (a) and (d), to Figure 1 in the manuscript (present day effects) there are many similarities including the general increase in grades across the Ohio Valley and Northern Rockies and Plains regions and along the west coast. These similarities suggest that the model projections are in line with what is already being observed with respect to changes in asphalt grade. The models project a continuation of these changes and eventual spreading of the required grade to nearly the entire United States.

\section{UnCERtainty Analysis of Projected Impacts}

The median estimates of true reliability for each region under RCP 4.5 and RCP 8.5 scenarios are shown in Figure S4 ( $a$ and $b$ ). We find that the Southeast and Ohio Valley regions are projected to see the greatest impact while the Northeast and Northwest regions are the least impacted. However, as noted earlier, considerable variation exists and thus there is a certain probability associated with each of these median projections. The region-wise cumulative distribution of the reliability was computed using the beta function to better understand the likelihood of impacts. The results are shown for RCP 4.5 and RCP 8.5 for all regions and for the 2040 base year (e.g., considering years 2040-2070) in Figure S4 (c and d). The figure shows that in addition to having the greatest median impacts, the projections for the Ohio Valley and Southeast regions also have the greatest uncertainty. This uncertainty generally tracks with the median values as the Northern Rockies and Plains and Southwest regions follow the Ohio Valley and Southeast regions in both median and spread. From this figure, it can also be observed that the Northwest and Western regions have an almost bimodal distribution in the case of RCP 4.5 projections. One group of models suggest little to no impacts in reliability while a second group project higher impacts. In RCP 8.5 the models tend to project a more consistent albeit skewed distribution. 


\section{Pavement Design Me Methodology}

The prediction of rutting and fatigue cracking in the Pavement Design ME model is a three-step process $^{26}$. First, the structural response (stresses and strains) to the applied truck load is predicted using layered elastic analysis. This prediction is made for each type of truck and load magnitude that the pavement is expected to experience. Since the properties of paving materials change according to climate (asphalt will be softer at high temperatures and soils will be affected by moisture), the predictions are repeated for each month of the analysis period (20 years) and for times representing the morning through the evening. Once this population of stresses and strains are known performance models are used to predict the fatigue damage, Equation (S1), and rutting damage, Equation (S2), that occurs from each truck, in each month, and for each time of the day.

$$
\begin{aligned}
& d_{i j k l}^{\text {fatiuge }}=\frac{n_{i j k l}}{\left.3.27 \times 10^{-5} \times 10^{4.84\left(\frac{V_{b}}{V_{b}+V_{a}}-0.69\right.}\right)\left(\varepsilon_{i j k l}^{f}\right)^{-3.291}\left(E_{k l}\right)^{0.854}} \\
& d_{i j k l}^{\text {rutting }}=\left(K_{1} 10^{-3.4488} T_{k l}\left(N_{i j k l}+N_{e}\right)^{0.479244}\right) \varepsilon_{i j k l}^{r}
\end{aligned}
$$

Where, $d_{i j k} k_{\text {fatigue }}=$ fatigue damage for truck $i$ at load $\mathrm{j}$ in month $k$ and time $l, n_{i j k l}=$ number of load applications at condition $i j k l, V_{b}=$ asphalt content, $V_{a}=$ air content of asphalt, $\&_{i j k l}^{f}=$ pavement strain response for fatigue at condition $i j k l, E_{k l}=$ elastic modulus of asphalt at condition $k l$ (modulus is not dependent upon truck or load). $d_{i j k l^{r}}{ }^{\text {ruting }}=$ rutting damage for condition $i j k l, K_{1}=$ constant dependent upon pavement thickness, $T_{k l}=$ temperature at condition $k l, \varepsilon^{r} i j k l=$ pavement strain response for rutting at condition $i j k l, N_{i j k l}=$ number of load applications at condition $i j k l$, and $N_{e}=$ the equivalent number of loads for condition $i j k l$ that exist due to all loadings prior to condition $i j k l$. The calculations proceed sequentially through each of the analysis combinations until the end of the 20-year analysis period. Once completed, the fatigue damage and permanent strains are converted to fatigue cracking and rutting using empirically calibrated transfer functions, Equations (S3) and (S4).

$$
\begin{aligned}
& F C=\left(\frac{100}{1+e^{-2\left(-2.40874-39.748(1+h)^{-2.856}\right)+\left(-2.40874-39.748(1+h)^{-2.856}\right) \log \sum d_{j i k t}^{\text {fitue }}}}\right) \\
& R D=\sum d_{i j k l}^{\text {rutting }} \times h
\end{aligned}
$$

Where, $F C=$ the percent of lane that is fatigue cracked, $R D=$ the rutting depth, and $h=$ the thickness of the asphalt concrete.

The result of this three-step process are predictions of fatigue cracking and rutting for each month of the pavement analysis period. Estimates of the standard error in these models, determined through empirical calibration, are then applied to the projected distresses to account for uncertainty in the models, materials, and traffic ${ }^{26}$. 
After using these models, we find that the predicted impact from choosing the incorrect asphalt grade varies more by roadway type than by climate region. In fact, the differences between climate regions Based on model predictions of the long-term pavement performance, an asphalt cement one standard grade below what is required leads to a $10 \%$ reduction in pavement life for interstates (coefficient of variation between predictions of 3.9\%) and a 15\% reduction for the other three roadways types (coefficient of variation of 5.6\%). When using an asphalt cement that is two standard grades below the required level, the pavement life for interstates, national routes, and state and local routes decline by $20 \%, 25 \%$ and $30 \%$, respectively (coefficients of variation of 5.8 , 7.1, and 9.6 respectively).

It is interesting to observe that in terms of a reduction in pavement life, the impact from an incorrect asphalt grade is greater for the thinner roadways than the thicker ones. This effect is attributed to the way heat transfers in a pavement system. Pavements, as a rule are warmer than the surrounding air since in addition to experiencing conductive heating by the air, they also experience additional heating by absorbing the shortwave radiation emitted by the sun. There are additional mechanisms that also occur, for example surface convections and heat released and stored in the supporting soil, but the interaction between climate and roadway type can be understood by simply considering the conduction and radiation mechanisms. For the two main mechanisms, the heating occurs at the surface and diffuses downward through the pavement structure (note that the reverse effect occurs when the air temperature drops and the sun sets). Thus, surface temperatures are the ones affected most greatly by increases in air temperature. The diffusion that takes place is also important and is affected by the total thermal mass of the pavement layers, the conductivity, specific heat, etc. While it is the cumulative effect of temperature across all layers that dictates pavement performance, a careful examination of Equations (S1) through (S4) reveals that the performance is weighted more heavily to loading that occurs at high-temperature ( $T$ is high, $E$ is low, and $\varepsilon$ is high). In roadways with a thicker asphalt concrete layer, the influence of surface temperature rise is mitigated first by having a larger thermal mass to reduce surface temperature rise the temperature, but also because the cumulative contribution of the surface damage to the total pavement damage decreases. By this same argument, when the wrong asphalt grade is used with thin pavements, the surface of the pavement is most greatly affected and the contribution of the damage that occurs at the surface is greater than it is in the case of the thick pavements. The net result of these phenomena is a greater loss in pavement life for lower class roadways relative to higher class roadways when temperature rise is not accounted for.

\section{Life Cycle Cost Analysis}

Projecting climate change impacts on pavement infrastructure and its engineering is complicated because the system contains multiple feedback loops that affect decision making. Engineers also have numerous strategies to address performance challenges and we recognize that they will likely respond to observed systematic decreases in performance, and can do so in many ways. For example, they could abandon the grading system entirely and make incremental empirical adjustments that that ultimately aligns with the new climatic reality. They could infer that errors exist in their engineering process and adjust their structural designs. They could also infer that changes to petroleum refining processes have negatively affected the asphalt cement and compensate by using asphalts modified with chemical or polymeric additives. While these changes will likely prevent the continuation of the status quo indefinitely, we assume for the purposes of 
estimating cost impacts, that it will take 30 years to recognize systematic reductions and incorporate broad changes into practice. This timeframe is assumed based on engineering practice that set pavement design life targets for initial construction and rehabilitation for pavements at the 15-20-year period, the total pavement life-cycle at 30-40 years, and the evolution of pavement design standards over the past 70 years (first established in the mid-1950s, and subsequent revision in the early-mid 1970s, early 1990s, and finally mid-2010s).

To establish the -1 and -2 grade schedule we adjust the timeline proportionally to the loss in pavement life. We use this simple approach to estimate the life cycle schedule when the incorrect asphalt is chosen because we assume that agencies will continue operating as they do now, by relying on decision matrices based upon the time when certain thresholds of performance thresholds are met (rutting, cracking, raveling, potholes, etc.). We recognize that this linear scaling is not a perfect representation of the pavement performance in individual years, but have adopted it for two specific reasons. First, most of the intermediate rehabilitations are related to pavement cracking phenomenon (crack sealing and patching), which do tend to grow linearly unless a pavement is poorly designed and experiences a near catastrophic failure. Within the analysis space we have adopted, it is assumed that engineers properly design and construct pavements and so these types of failures do not occur. The larger rehabilitations (overlays) occur within a few years of the pavement life predicted from the Pavement Design ME performance model so the extrapolation errors in the timing of these events is small. More sophisticated approaches would require establishing probability distributions for costs, timings, partial maintenance, and constrained economics of agencies. Such approaches can be characterized accurately for only specific project level conditions. Here, we are conducting a large network analysis and believe that these approaches would introduce even greater uncertainty to the analysis.

After carrying out the LCCA for the network we find that the median cost impact across the US based on RCP 4.5 are US\$13.6, US\$19.0, and US\$21.8 billion in 2010, 2040, and 2070, respectively. The interquartile range for these estimates are approximately $22 \%$ of these median costs (US\$3.1, US\$3.8, and US\$5.5 billion respectively). If these costs are annualized over the entire 30-year life cycle, then median annualized cost estimates become US\$0.8, US\$1.1, and US $\$ 1.3$ billion. Total cost estimates based on RCP 8.5 are US $\$ 14.5$, US $\$ 26.3$, and US $\$ 35.8$ billion, respectively. The interquartile range for these cases is $15-22 \%$ of the median costs (US $\$ 2.3$, US\$3.9, and US\$7.6 billion for 2010, 2030, and 2070 respectively) and annualized costs are US\$0.8, US\$1.5, and US\$2.1 billion (again for 2010, 2030, and 2070 respectively). As expected, as more time passes the differences in costs between the RCP 8.5 and RCP 4.5 scenarios increases from $7.1 \%$ for the 2010 period to $64 \%$ for the 2070 period.

From Figure S5, we also find that the total costs of failing to adapt to the projected changes disproportionately affect the Ohio Valley, South, and Southeast regions, which collectively account for approximately $54 \%$ of the total costs. Also based on total cost we find that the four states most likely to experience elevated costs are Illinois, Texas, Florida, and California. Interestingly, the projected impacts in Texas substantially increase in RCP 8.5 scenario compared to the RCP 4.5 and scenario. These results are not entirely surprising as these states also have relatively large transportation networks. 
We also present the cost per lane kilometer to account for differences in the state-level infrastructure network, Figure S6. This standardization produces similar results across states and regions but with some notable differences. The Ohio Valley and Southeast regions will experience the greatest costs, especially under RCP 4.5. When comparing the RCP 4.5 and RCP 8.5 scenarios, we also find that the Upper Midwest, Southern, Western, and Northeastern regions, along with the Ohio Valley and Southeast, are most sensitive to the RCP scenario. The results are most dramatic for the Upper Midwest, where the difference in cost by RCP varies by almost $90 \%$. Other states that show high per kilometer cost differences between RCP scenarios are Ohio (75\%), Delaware (75\%), North Dakota (74\%), New Jersey (72\%), and Arkansas (68\%). Conversely, Massachusetts, Maine, New Hampshire, Rhode Island, Vermont, Mississippi, and Alabama show small differences between the two scenarios.

Finally, we also see that for a given scenario (RCP 4.5 or RCP 8.5) states have different levels of agreement between the models. In the most extreme case, Delaware under RCP 4.5, there is an estimated range of per lane kilometer costs between US\$0 and US\$16,500. Under RCP 8.5, the non-outlying predictions yield uniform agreement of US\$16,500. This pattern of model convergence and then separation can be related to the discrete grade increments in the grading system. We find that states along the east coast (Northeast, Ohio Valley, and Southeast) have a greater range in projected costs under RCP 4.5 than RCP 8.5, states in the South, Southwest, Northwest, West, and Northern Rockies and Plains have approximately equal range, while those in the Upper Midwest show a greater range under RCP 8.5.

We also investigate the contribution of these costs by roadway type using the RCP 8.5 scenario. We analyze RCP 8.5 only because the results mostly parallel those from RCP 4.5 . This analysis assesses the administrative responsibility for the costs because state highway agencies oversee interstate, national routes, and state routes while local streets and residential streets are often the responsibility of municipalities. These municipalities often have fewer options with respect to generating revenue, and hence covering the expected costs. We find based on this analysis that the local roads constitute approximately $4 \%$ of the cost burden, while state routes comprise the greatest proportion at $40 \%$. These estimates; however, cannot account for residential streets, which constitute more than $66 \%$ of the total lane distance of roads in the United States ${ }^{27}$. This information is not available for many locations and is not in the public database, and since the engineering and maintenance of these residential streets differs substantially from the other roadway types the cost impact is not proportionate to their length and is note estimated here. Nevertheless, the inability to account for this residential network means that the impacts quantified here represent lower cost estimate, particularly for municipal and county road agencies whose networks are primarily madeup of residential streets. We expect that states containing relatively large lengths of local roads would also have larger proportions of unaccounted for residential streets. Figure S7 shows the percentage of each roadway type used in the analysis here. This graphic demonstrates that some states do have a proportionately larger number of local streets and hence likely a larger proportion of roads that are unaccounted for in the current analysis. States with the largest proportion of these streets are California, Washington, New Jersey, and Nevada.

\section{COMPARISON With OTHER RESUlts}

The economic assessment here is somewhat biased to underestimating the true cost of temperature related effects since we do not account for costs due to construction delays from more frequent 
activities and increased vehicle operating costs because of degenerated pavement quality. These impacts carry a real economic burden, but estimates of their cost are difficult and/or vary geographically. Apart from the true capital infrastructure cost, these less apparent and more difficult to quantify factors are an important burden to government agencies and the public. In addition, the process of delivering and maintaining the pavement infrastructure carries an environmental burden. More frequent maintenance activities could thus result in environmental impacts. Although we focus here only on the economic impact, the exact environmental effects could be mitigated by selecting more environmentally friendly and sustainability minded strategies.

Only one other national estimate of cost similar in scope to what is done here has been identified in the literature. Chinowsky et al. estimated annualized costs of between US $\$ 0.75$ and US $\$ 0.52$ billion depending on the year of analysis ${ }^{3}$. These values are similar, but lower to the costs that we have estimated. There are other, more subtle differences though like the fact that our analysis suggest that the costs will increase over time, while the others suggest a decreasing cost with time. As discussed in Supplementary Section 1, the method adopted by Chinowsky et al. (and the related papers by the same research group) estimate costs by assuming perfect adaptation into engineering practice, whereas our estimates are based on the question of failing to adapt, which explains the differences in cost impacts over time. There are also differences in how we are estimating material costs and how we estimate the performance of pavements. Nevertheless, these differing scenarios would seemingly represent the range of future possibilities and thus a comparative range of costs.

There have been a few localized studies of cost impacts that should be mentioned. Larsen et al. applied an adaptation approach (a precursor to the one used by Chinowsky et al.) and estimated the per $\mathrm{km}$ costs in Alaska for the period from 2006 to 2080 at between US\$58,421 and US $\$ 42,545^{28}$. Annualizing these costs (using the same discount rate that Larsen used) results in estimates of between US\$1,762 and \$1,283 per lane $\mathrm{km}$. Our estimates of annualized per km costs range from US\$978 (Missouri under RCP 8.5) to US\$79 (Connecticut under RCP 4.5). That Alaska might have a higher annualized impact is not surprising since evidence has suggested higher warming there than the rest of the contiguous U.S..$^{29}$ However, this could also be related to the fact that performance losses were based on the authors' own judgements and not supported with any performance modeling. A more recent investigation of the same Alaskan network using the same model as in Chinowsky et al. ${ }^{3}$ results in number that are overall smaller than those estimated in the 2008 effort, but individual lane $\mathrm{km}$ costs are not reported ${ }^{30}$.

Mallick et al. estimated maintenance cost increases of more than $160 \%$ by 2100 for a relatively thin asphalt surfaced pavement ${ }^{31}$. This cost is greater than what we estimate, but could be related to aggressive estimates of the impact of temperature on material properties, focus on a coastal roadway, and inclusion of soil saturation changes. Unfortunately, there are not enough details presented to postulate with greater certainty on other underlying causes. Qia et al. estimated a considerably smaller estimate of cost increase (1-2\%) through $2050^{15}$. There are a few relevant details that explain the difference between their estimate and the one developed in this paper. First, the authors considered only a single location and with a single GCM (high, medium, and low emission scenarios were considered though). Second, temperature was incorporated by linear scaling of all future climate according to the median annual predicted temperature rise. Pavement performance is more greatly affected by high temperatures and scaling by the annual air 
temperature increase does not consider future predictions of extreme hot (or cold) days. Finally, the estimate of $1-2 \%$ is based on a selection of optimal treatment options throughout the lifetime. In this case the estimate can be seen as another "best case scenario" assessment that taken in contrast to the estimates here (3-9\% increases) provides an important perspective on the importance of quickly adapting to a non-stationary future.

\section{REFERENCES}

1. Cambridge Systematics, Inc. (2015). Central Texas Extreme Weather and Climate Change Vulnerability Assessment of Regional Transportation Infrastructure. FHWA No. 0704-0188. Capital Area Metropolitan Planning Organization, Austin TX.

2. Chinowsky, P.\& C. Arndt . Climate Change and Roads: A Dynamic Stressor-Response Model. Review of the Development Economics, 16(3), pp. 448-462. doi: 10.1111/j.14679361.2012. 00673.x

3. Chinowsky, P.S., J.C. Price, \& J.E. Neumann (2013). Assessment of Climate Change Adaptation Costs for the US Road Network. Global Environmental Change, 23(4), 764-773. doi: 10.1061/9780784413326.

4. Schweikert, A., P. Chinowsky, S. Espinet, \& M. Tarbert (2014). Climate Change and Infrastructure Impacts: Comparing the Impact on Roads in Ten Countries through 2100. Procedia Engineering, 78, 306-316. doi: 10.1016/j.proeng.2014.07.072

5. Viola, F. \& C. Celauro (2015). Effect of Climate Change on Asphalt Binder Selection for Road Construction in Italy. Transportation Research Part D: Transport and Environment, 37, 40-47. doi: $10.1016 /$ j.trd.2015.04.012

6. Fletcher, C.G., L. Matthews, J. Andrey, \& A. Saunders (2016). Projected Changes in MidTwenty-First-Century Extreme Maximum Pavement Temperature in Canada. Journal of Applied Meteorology and Climatology, 55(4), 961-974. doi: 10.1175/JAMC-D-15-0232.1

7. Harvey, M., P. Whetton, K.L. McInnes, B. Cechet, J.L. McGregor, K. Nguyen, N. Houghton, C. Lester, E. Styles, N. Michael, \& T. Martin (2004). Impact of Climate Change on Road Infrastructure. Austroads Report No. AP-R243/04. Austroads and the Bureau of Transport and Regional Economics, Sydney.

8. Meagher, W., J.S. Daniel, J. Jacobs, \& E. Linder (2012). Method for Evaluating Implications of Climate Change for Design and Performance of Flexible Pavements. Transportation Research Record: Journal of the Transportation Board, 2305, 111-120. doi: 10.3141/2305-12

9. Mills, B.N., S.L. Tighe, J. Andrey, J.T. Smith, \& K. Huen (2009). Climate Change Implications for Flexible Pavement Design and Performance in Southern Canada, Journal of Transportation Engineering 135(10), 773-782. doi: 10.1061/(ASCE)0733-947X

10. Mndawe, M.B., J. Ndambuki, \& W.K. Kupolati (2013). Revision of the Macro Climatic Regions of Southern Africa. OIDA International Journal of Sustainable Development, 6(1) 3744.

11. Daniel, J.S, J.M. Jacobs, E. Douglas, R.B. Mallick, \& K. Hayhoe (2014). Impact of Climate Change on Pavement Performance: Preliminary Lessons Learned through the Infrastructure and Climate Network (ICNet), In International Symposium of Climatic Effects on Pavement and Geotechnical Infrastructure 2013, Fairbanks AK. doi: 10.1061/9780784413326

12. Huang, Y.H. (1993). Pavement Analysis and Design. Prentice Hall, Upper Saddle River, NJ.

13. Yoder, E.J., \& M.W. Witczak (1975). Principles of Pavement Design. John Wiley \& Sons, New York, NY. 
14. Mallick, R.B., J.M. Jacobs, B.J. Miller, J.S. Daniel, \& P. Kirshen (2016). Understanding the Impact of Climate Change on Pavements with CMIP5, System Dynamics and Simulation, International Journal of Pavement Engineering, In Press. doi: 101080/10298436.2016. 1199880

15. Qiao, Y., A.R. Dawson, T. Parry, \& G.W. Flintsch (2015). Evaluating the Effects of Climate Cange on Road Maintenance Intervention Strategies and Life-Cycle Costs. Transportation

Research Part D: Transport and Environment, 41, 492-503. doi: 10.1080/10298436.2016. 1199880

16. Bergek, A., S. Jacobsson, B. Carlsson, S. Lindmark, \& A. Rickne (2008). Analyzing the Functional Dynamics of Technological Innovation Systems: A scheme of Analysis, Research Policy, 37(3), 407-429. doi: 10.1016/j.respol.2007.12.003

17. Carlsson, B., \& S Jacobsson (1997). In Search of Useful Public Policies - Key Lessons and Issues for Policy Makers. Chapter 10 in Technological Systems and Industrial Dynamics, Ed. B. Carlsson, Springer US.

18. Kieft, A., R. Harmsen, \& M.P. Hekkert (2016). Interactions Between Systemic Problems in Innovation Systems: The case of Energy-Efficient Houses in the Netherlands, Environmental Innovation and Societal Transitions, In Press. doi: 10.1016/j.eist.2016.10. 001

19. Negro, S.O., F. Alkemade, \& M.P. Hekkert, (2012). Why Does Renewable Energy Diffuse so Slowly? A Review of Innovation System Problems, Renewable and Sustainable Energy Reviews, 16(6), 3836-3846. doi: 10.1016/j.rser.2012.03.043

20. Wieczorek, A.J., \& M.P. Hekkert (2012). Systemic Instruments for Systemic Innovation Problems: A Framework for Policy Makers and Innovation Scholars, Science and Public Policy, 39(1), 74-87. doi: 10.1093/scipol/scr008

21. Martin, R., \& P. Sunley (2006). Path Dependence and Regional Economic Evolution, Journal of Economic Geography, 6(4), 395-437. doi: 10.1093/jeg/lb1012

22. Geels, F.W., \& R. Kemp (2007). Dynamics in Socio-Technical Systems: Typology of Change Processes and Contrasting Case Studies, Technology in Society, 29(4), 441-455. doi: 10.1016/j.techsoc.2007.08.009

23. Smith, A., A. Stirling, \& F. Berkhout (2005). The Governance of Sustainable Socio-Technical Transitions, Research Policy, 34(10), 1491-1510. doi: 10.1016/j.respol.2005. 07.005

24. Casey, D., P. Casey, \& A.C. Lemer (2012). Tracing Innovation's Spread: Impacts of the Domestic Scan Program, TR News, 278, 3-8. Online < http://onlinepubs.trb.org/ onlinepubs/trnews/trnews278.pdf $>$ Accessed August 2016.

25. National Cooperative Highway Research Program (2016). US Domestic Scan Program, National Cooperative Highway Research Program Project 20-68A(02). Online $<\underline{\text { http://apps.trb.org/cmsfeed/TRBNetProjectDisplay.asp?ProjectID }=1570>\text { Accessed August }}$ 2016.

26. Applied Research Associates (ARA) (2004). Guide for Mechanistic-Empirical Design of New and Rehabilitated Pavement Structures. Final Report. NCHRP 1-37A. National Cooperative Highway Research Program, National Research Council, Washington, DC.

27. United States Department of Transportation (USDOT) (2016). National Transportation Statistics. Bureau of Transportation Statistics, Washington, DC. Online < https://www.rita.dot.gov/bts/sites/rita.dot.gov.bts/files/publications/national_transportation_st atistics/index.html >. Accessed March 2016. 
28. Larsen, P.H., S. Goldsmith, O. Smith, M.L. Wilson, K. Strzepek, P. Chinowsky, \& B. Saylor (2008). Estimating Future Costs for Alaska Public Infrastructure at Risk from Climate Change, Global Environmental Change, 18(3), 442-457. doi: 10.1016/j.gloenvcha.2008. 03.005 .

29. Chapin, F.S., S.F. Trainor, P. Cochran, H. Huntington, C. Markon, M. McCammon, A.D. McGuire, \& M. Serreze (2014). Ch. 22: Alaska. Climate Change Impacts in the United States. The Third National Climate Assessment, J.M. Melillo, T.C. Richmond, \& G.W. Yohe, Eds, U.S. Global Change Research Program, 514-536.

30. Melvin, A.M., P. Larsen, B. Boehlert, J.E. Neumann, P. Chinowsky, X. Espinet, J. Martinich, M.S. Baumann, L. Rennels, A. Bothner, D.J. Nicolsky, \& S.S. Marchenko (2016). Climate Change Damages to Alaska Public Infrastructure and the Economics of Proactive Adaptation, Proceedings of the National Academy of Sciences, 114(2), 122-131. doi: 10.1073/pnas. 1611056113.

31. Mallick, R., M. Radzicki, J. Daniel, \& J. Jacobs (2014). Use of System Dynamics to Understand Long-Term Impact of Climate Change on Pavement Performance and Maintenance Most, Transportation Research Record: Journal of the Transportation Research Board, 2455, 1-9. doi: 10.3141/2455-01 
(a)

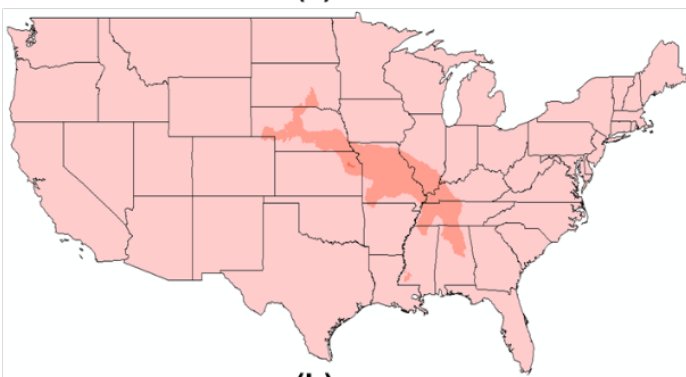

(b)

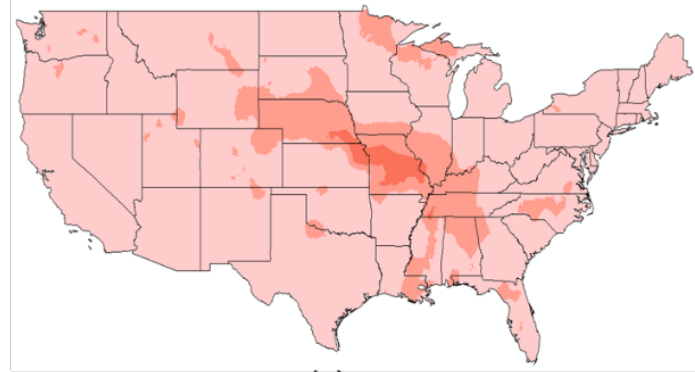

(c)

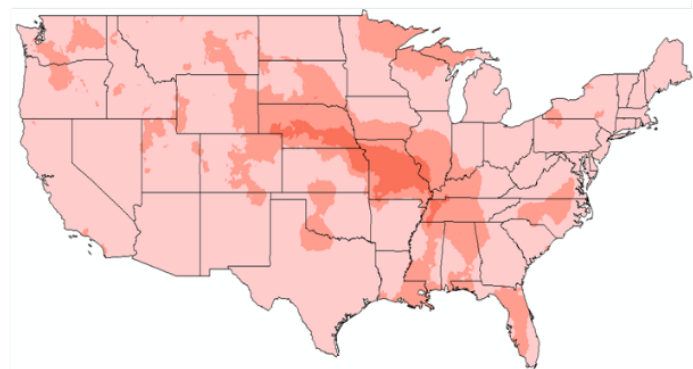

Change in High Temperature $\left({ }^{\circ} \mathrm{C}\right)$

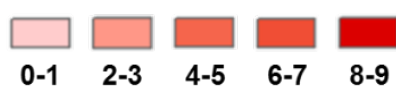

(d)

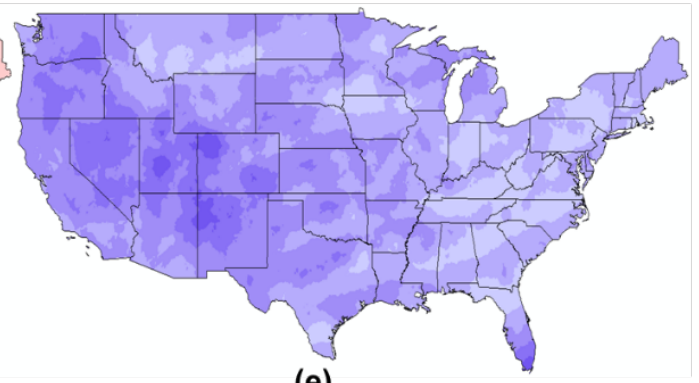

(e)

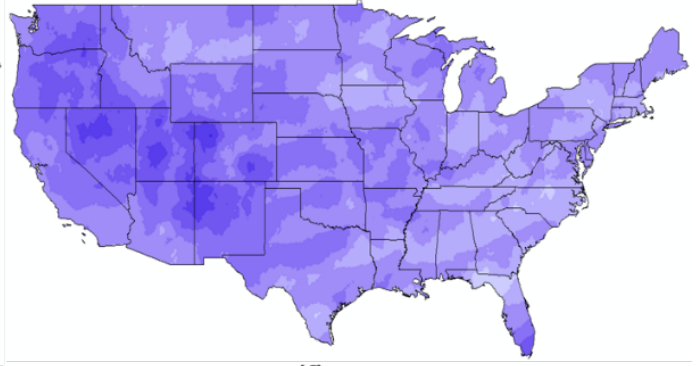

(f)

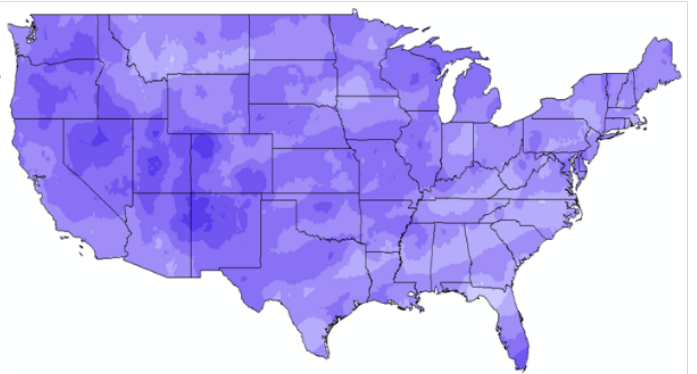

Change in Low Temperature $\left({ }^{\circ} \mathrm{C}\right)$

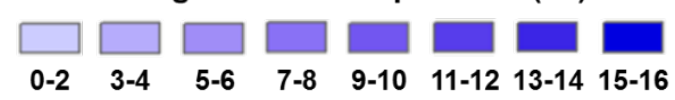

Figure S1. Expected median increases in pavement temperature based on the RCP 8.5 ensemble: (a-c) average 7-day maximum temperature and (d-f) average minimum temperature changes for 2010-39, 2040-69, and 2070-99 respectively relative to the 1966-1995 climatology. Darker colored contours indicate locations where the pavement temperatures will exceed current stationarity implied pavement temperatures by a greater level and thus experience greater performance impacts. 
(a)

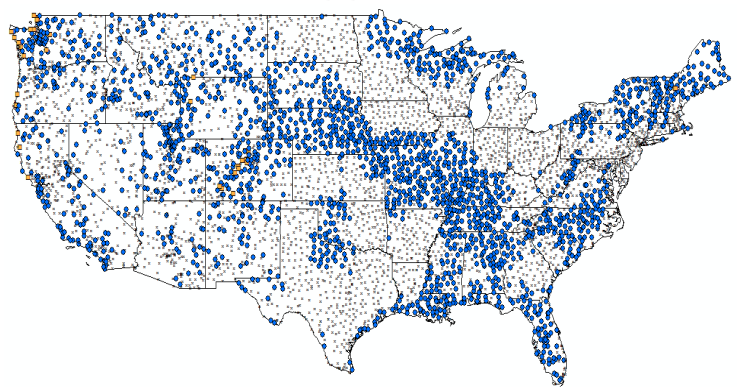

(b)

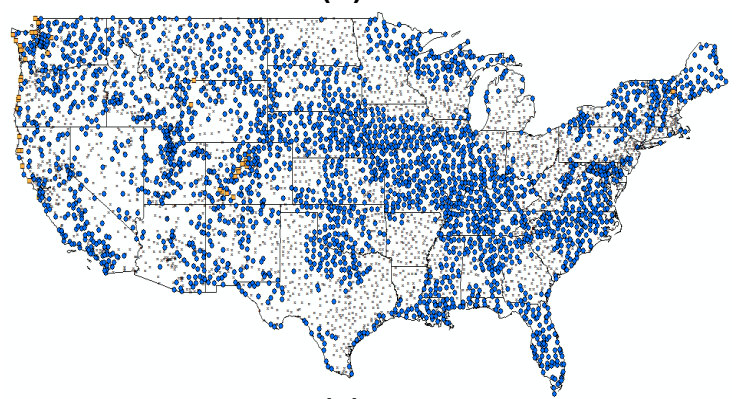

(c)

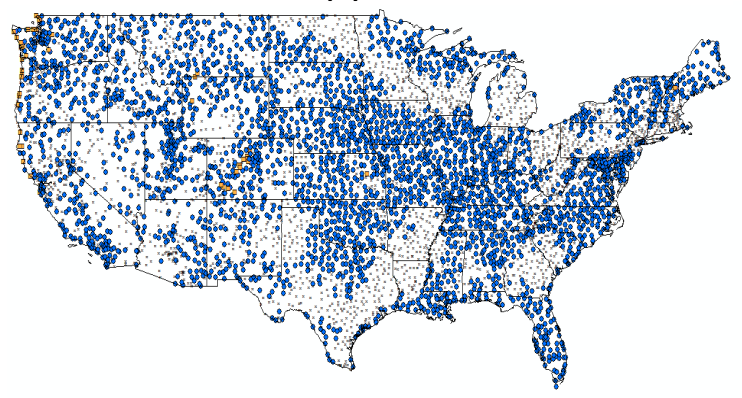

Number of Standard Grade Changes (d)

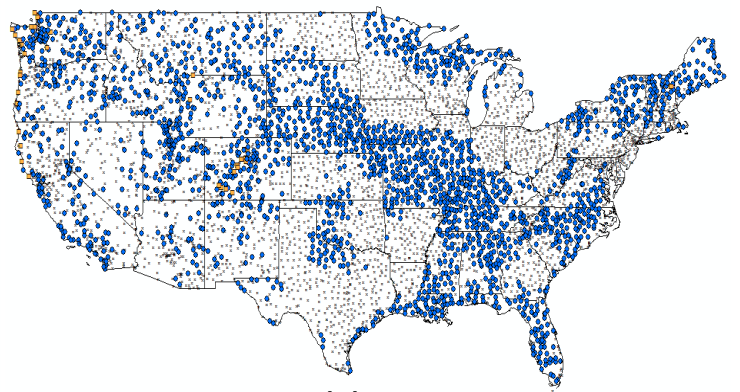

(e)

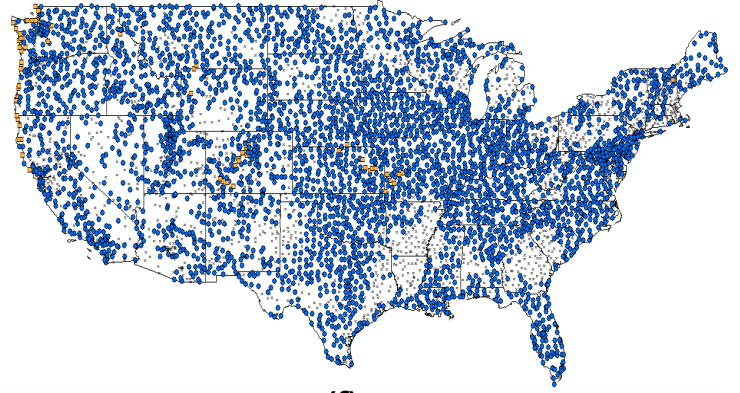

(f)

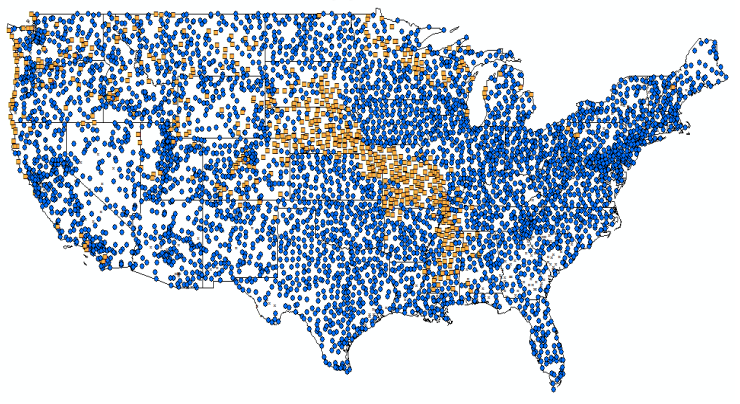

$\begin{array}{lll}\times & 0 & \\ 0 & 1 & 2\end{array}$

Figure S2. Expected number of increases in the standard high temperature grade increment for: (a-c) RCP 4.5 and for (a) 2010-2039, (b) 2040-2069, and (c) 2070-2099 and (d-f) RCP 8.5 and for (d) 2010-2039, (e) 2040-2069, and (f) 2070-2099. Blue circles indicate 1 grade change, orange squares indicate 2 grade changes, and black cross marks indicate no change. 


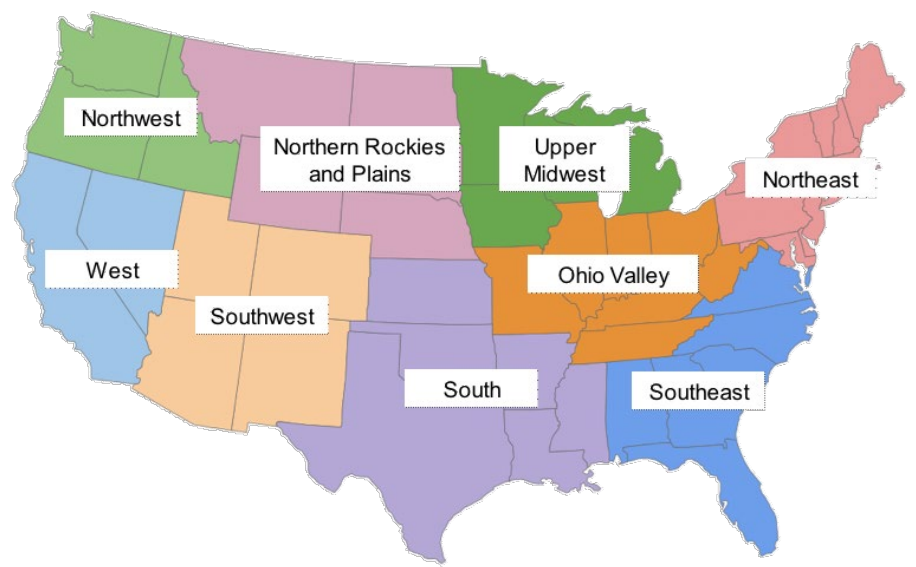

Figure S3. Regional boundaries used for this study.
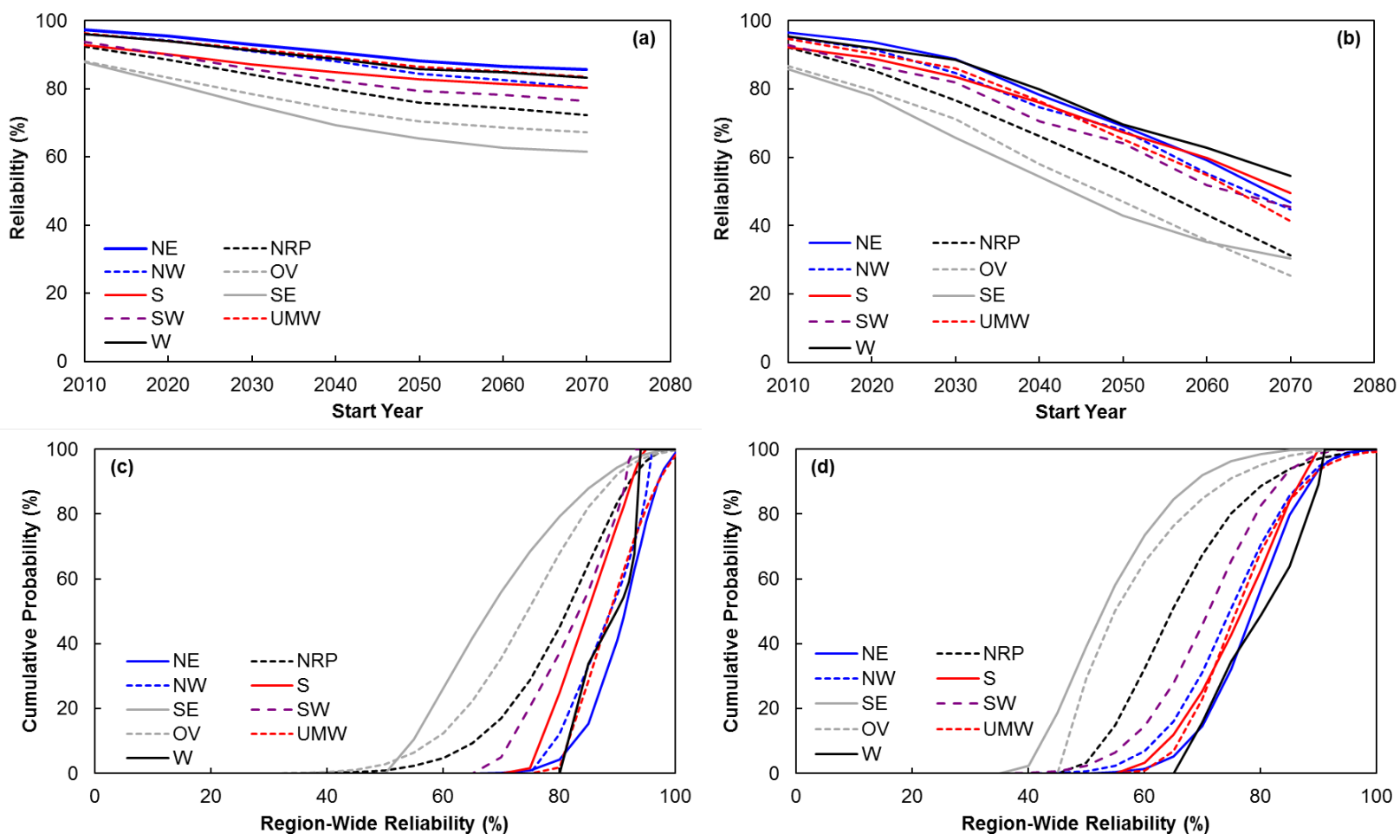

Figure S4. ( $a$ and $b$ ) Multimodal ensemble median predicted reliability by region for ( $a$ ) $R C P$ 4.5 and (b) RCP 8.5; ( $c$ and d) Cumulative probability distributions for regional reliability for (a) RCP 4.5 and (b) RCP 8.5 (Legend indicates region of interest, $N E=$ Northeast, $N R P=$ Northern Rockies and Plains, $N W=$ Northwest, $O V=$ Ohio Valley, $S=$ South, $S E=$ Southeast, $S W=$ Southwest, $U M W=$ Upper Midwest, and $W=W e s t)$. 

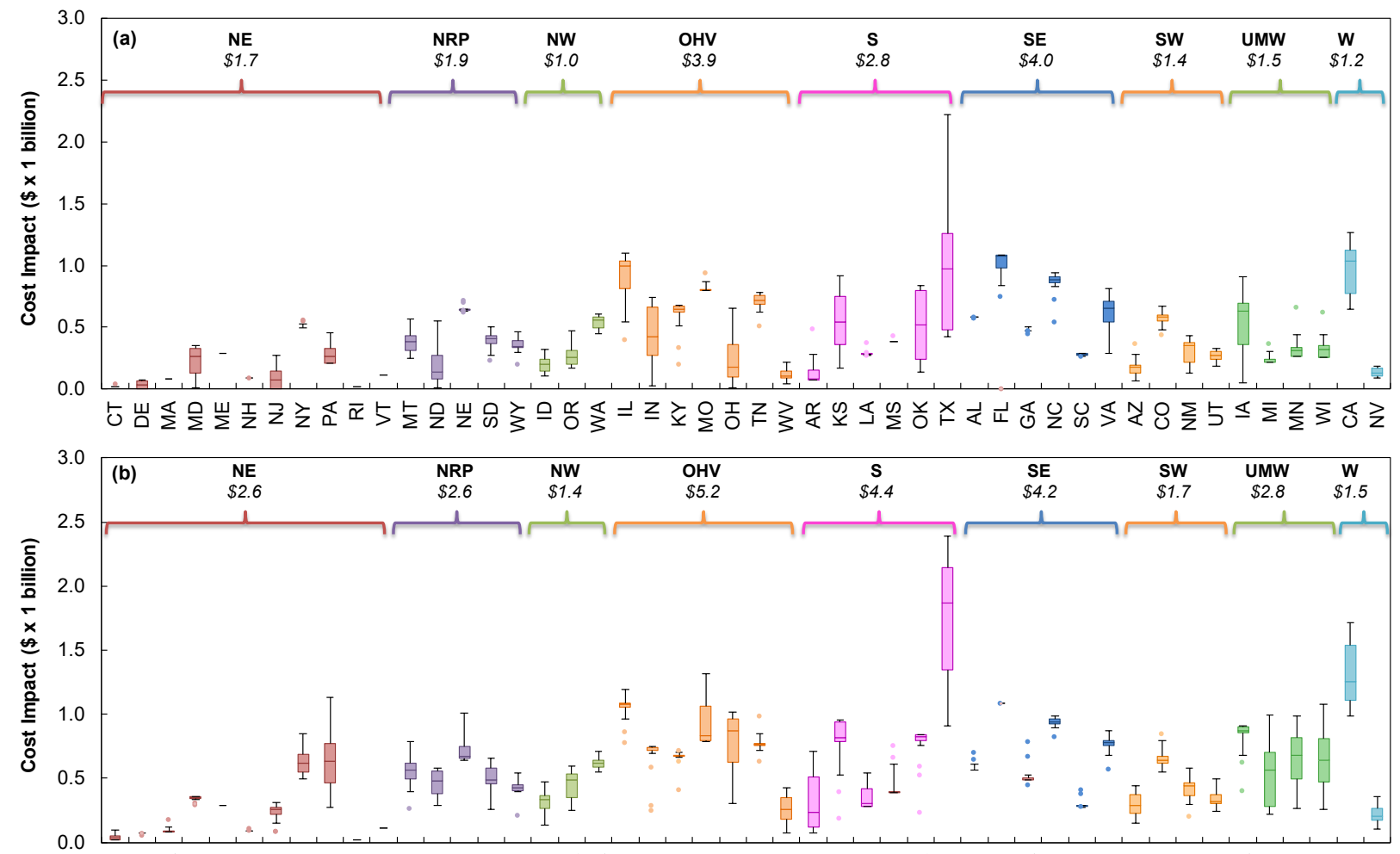

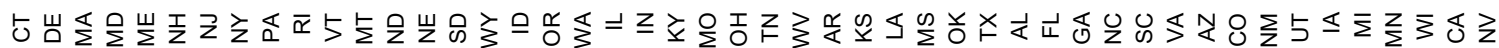

Figure S5. Projected median cost impact to pavement infrastructure on a total cost basis for 2040-2070 period from failing to successfully adapt asphalt cement grade; (a) RCP 4.5 and (b) RCP 8.5 (note costs are in US\$ $x 1$ billion). The boxed areas enclose the 75th and 25th percentile range from the model ensemble. The horizontal line in these boxes is the median and the error bars show the maximum and minimum costs from the models in the ensemble. Outliers are plotted as single dots. 


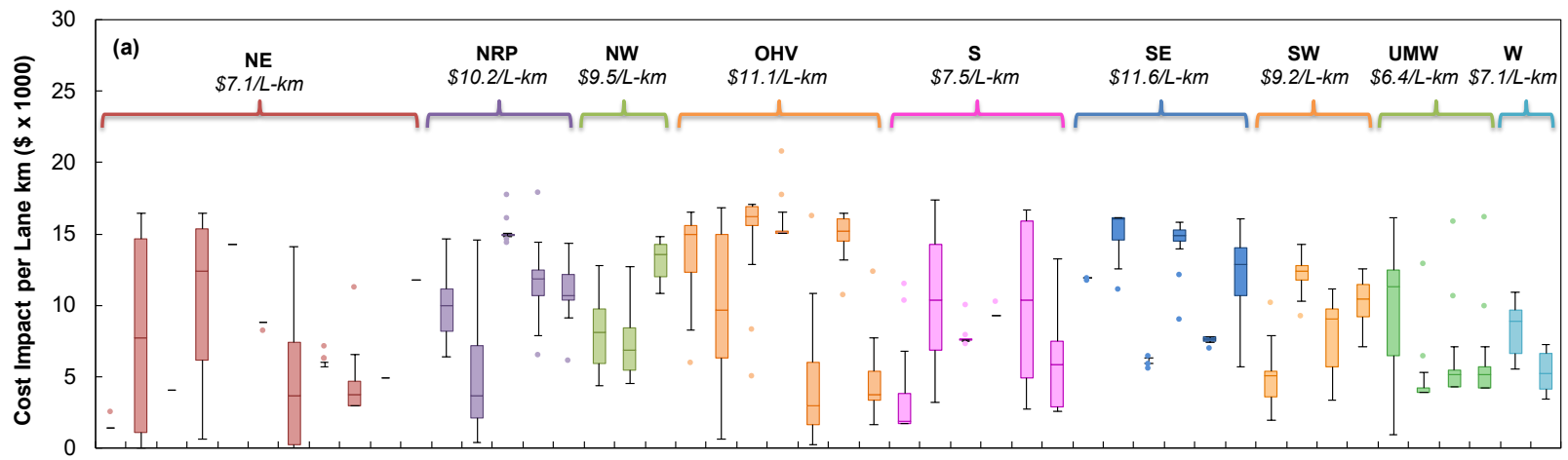

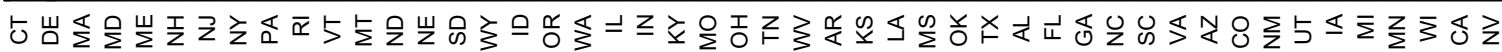

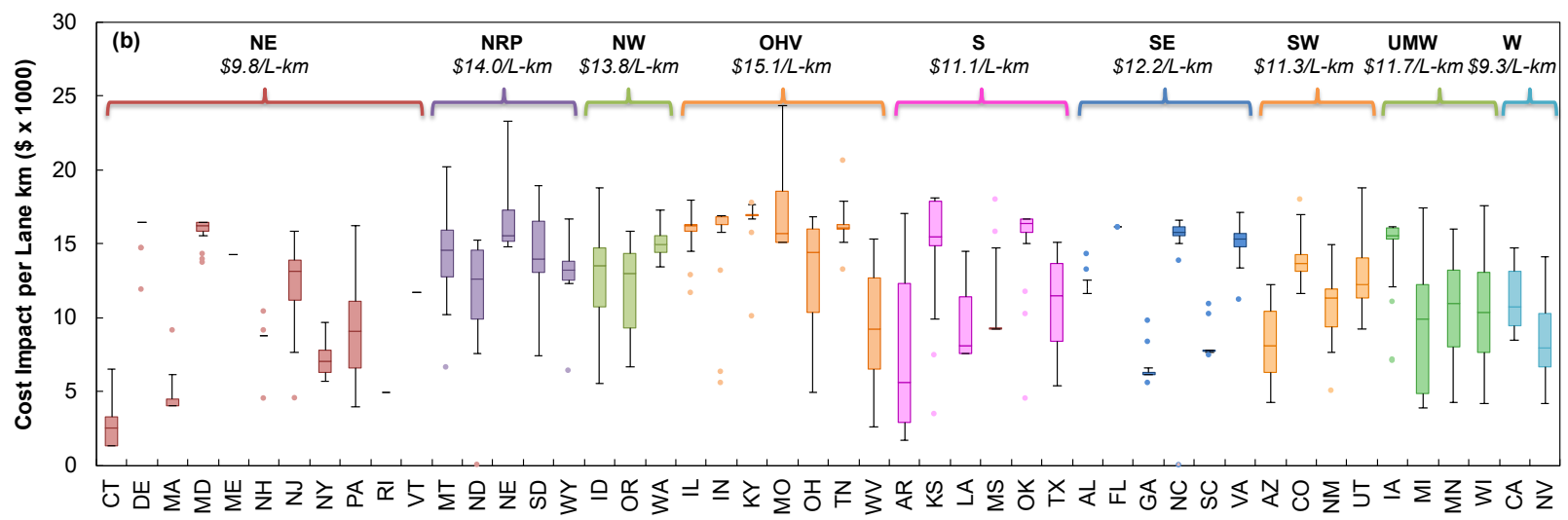

Figure S6. Projected median cost impact to pavement infrastructure on a per-lane kilometer basis for 2040-2070 period from failing to successfully adapt asphalt cement grade; (a) RCP 4.5 and (b) RCP 8.5 (note average costs are in US\$ $x$ 1000). The boxed areas enclose the 75th and 25 th percentile range from the model ensemble. The horizontal line in these boxes is the median and the error bars show the maximum and minimum costs from the models in the ensemble. Outliers are plotted as single dots.

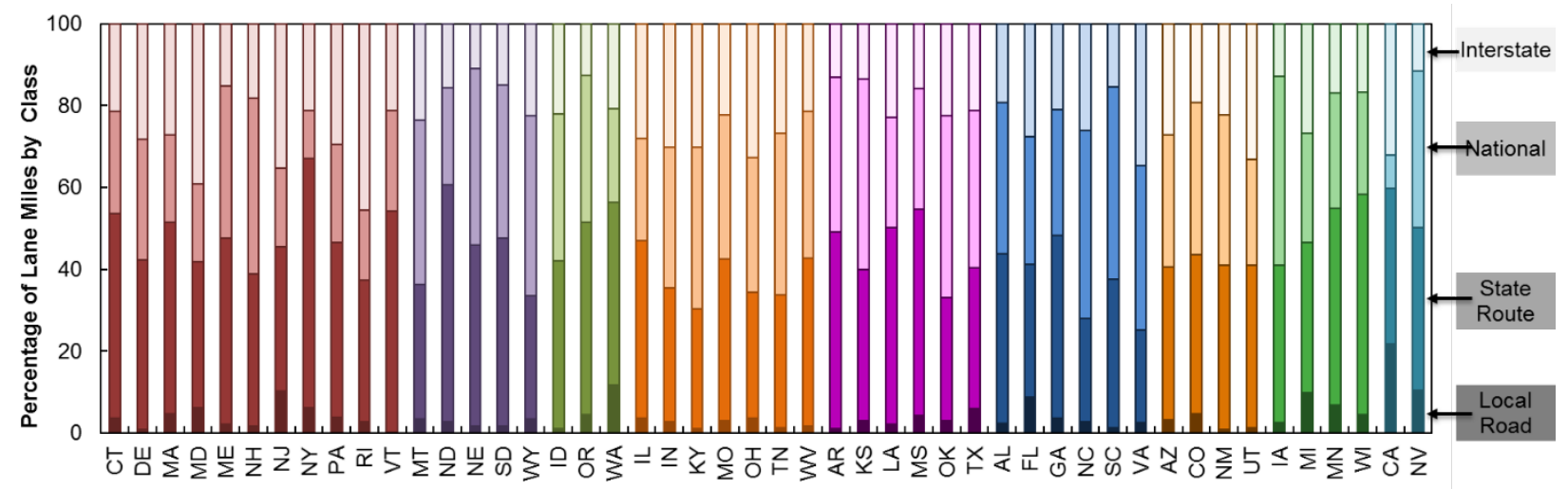

Figure S7. Percentage of roadways in analysis dataset by roadway type and by state. 
Table S1. Summary of Climate Models Used in this Study.

\begin{tabular}{lcc}
\hline \multicolumn{1}{c}{ Modeling Center (or Group) } & Institute ID & Model Name \\
\hline $\begin{array}{l}\text { Commonwealth Scientific and Industrial Research Organization } \\
\text { (CSIRO) and Bureau of Meteorology (BOM), Australia }\end{array}$ & CSIRO-BOM & ACCESS1.0 \\
$\begin{array}{l}\text { Beijing Climate Center, China Meteorological Administration } \\
\text { Canadian Centre for Climate Modeling and Analysis }\end{array}$ & BCC & BCC-CSM1.1 \\
$\begin{array}{l}\text { National Center for Atmospheric Research } \\
\text { Community Earth System Model Contributors }\end{array}$ & CCMAS & CCSM4 \\
$\begin{array}{l}\text { Centre National de Recherches Météorologiques / Centre } \\
\text { Européen de Recherche et Formation Avancée en Calcul }\end{array}$ & NSF-DOE-NCAR & CESM1(BGC) \\
$\begin{array}{l}\text { Scientifique } \\
\text { Commonwealth Scientific and Industrial Research Organization } \\
\text { in collaboration with Queensland Climate Change Centre of }\end{array}$ & CNRM-CERFACS & CNRM-CM5 \\
$\begin{array}{l}\text { Excellence } \\
\text { NOAA Geophysical Fluid Dynamics Laboratory }\end{array}$ & & \\
$\begin{array}{l}\text { Institute for Numerical Mathematics } \\
\text { Institut Pierre-Simon Laplace }\end{array}$ & NOAA GFDL & GFDL-ESM2G \\
$\begin{array}{l}\text { Japan Agency for Marine-Earth Science and Technology, } \\
\text { Atmosphere and Ocean Research Institute, and National Institute } \\
\text { for Environmental Studies }\end{array}$ & INM & IFDL-ESM2M \\
$\begin{array}{l}\text { Max Planck Institute for Meteorology } \\
\text { Meteorological Research Institute }\end{array}$ & IPSL & IPSL-CM5A-LR \\
Norwegian Climate Centre & & IPSL-CM5A-MR \\
\hline
\end{tabular}


Table S2. Construction, Maintenance, and Rehabilitation Schedule Considered for LCCA analysis.

\begin{tabular}{|c|c|c|c|c|c|c|}
\hline \multirow{3}{*}{ Activity } & \multicolumn{6}{|c|}{ Year of Activity } \\
\hline & \multirow{2}{*}{$\begin{array}{c}\text { Correct Grade } \\
\text { Schedule } \\
\text { All Roadway } \\
\text { Types }\end{array}$} & \multicolumn{2}{|c|}{-1 Standard Grade Schedule } & \multicolumn{3}{|c|}{-2 Standard Grades Schedule } \\
\hline & & Interstate & $\begin{array}{l}\text { National, State, } \\
\text { and Local Routes }\end{array}$ & Interstate & $\begin{array}{c}\text { National } \\
\text { Routes }\end{array}$ & $\begin{array}{c}\text { State and Local } \\
\text { Routes }\end{array}$ \\
\hline Construction & 0.0 & 0.0 & 0.0 & 0.0 & 0.0 & 0.0 \\
\hline Crack Sealing & 4.0 & 3.5 & 3.5 & 3.0 & 3.0 & 3.0 \\
\hline Patching & 8.0 & 7.0 & 6.5 & 6.0 & 6.0 & 5.5 \\
\hline Crack Sealing & 10.0 & 9.0 & 8.5 & 8.0 & 7.5 & 7.0 \\
\hline Patching & 13.0 & 11.5 & 11.0 & 10.0 & 9.5 & 9.0 \\
\hline Milling $^{1}$ & 16.0 & 14.0 & 13.5 & 12.5 & 12.0 & 11.0 \\
\hline Overlay $^{1}$ & 16.0 & 14.0 & 13.5 & 12.5 & 12.0 & 11.0 \\
\hline Crack Sealing & 19.0 & 17.0 & 16.0 & 15.0 & 14.0 & 13.0 \\
\hline Patching & 22.0 & 19.5 & 19.0 & 17.5 & 16.5 & 15.0 \\
\hline Crack Sealing & 25.0 & 22.5 & 21.0 & 20.0 & 18.5 & 17.5 \\
\hline Patching & 27.0 & 24.0 & 23.0 & 21.5 & 20.0 & 18.5 \\
\hline Milling $^{1}$ & -- & 27.0 & 25.5 & 24.0 & 22.5 & 21.0 \\
\hline Overlay $^{1}$ & -- & 27.0 & 25.5 & 24.0 & 22.5 & 21.0 \\
\hline Crack Sealing & -- & -- & 28.0 & 26.5 & 24.5 & 23.0 \\
\hline Patching & -- & -- & -- & 28.5 & 27.0 & 25.0 \\
\hline Crack Sealing & -- & -- & -- & & 29.0 & 27.0 \\
\hline Salvage Value & 0.00 & 0.75 & 0.67 & 0.50 & 0.33 & 0.20 \\
\hline
\end{tabular}


Table S3. Inputs used for AASHTO Pavement Design ME Simulations.

\begin{tabular}{|c|c|c|c|c|}
\hline Climate & $\begin{array}{l}\text { State } \\
\text { Weather Station }\end{array}$ & $\begin{array}{c}\text { Minnesota } \\
\text { Minneapolis }(94963)^{1}\end{array}$ & $\begin{array}{c}\text { Florida } \\
{\text { Miami }(12839)^{1}}^{1}\end{array}$ & $\begin{array}{c}\text { North Carolina } \\
\text { Raleigh }(13722)^{1}\end{array}$ \\
\hline \multirow{5}{*}{$\begin{array}{c}\text { Asphalt } \\
\text { Concrete } \\
\text { Layer }\end{array}$} & Asphalts & $\begin{array}{c}\text { PG 58-34, PG 52-34, } \\
\text { PG 46-34 }\end{array}$ & $\begin{array}{c}\text { PG 70-10, PG 64-10, } \\
\text { PG 58-10 }\end{array}$ & $\begin{array}{c}\text { PG } 64-22, \text { PG 58-22, } \\
\text { PG 52-22 }\end{array}$ \\
\hline & Interstate Thickness $(\mathrm{cm})$ & 25.4 & 25.4 & 25.4 \\
\hline & National Route Thickness (cm) & 15.2 & 15.2 & 15.2 \\
\hline & State Route Thickness $(\mathrm{cm})$ & 10.2 & 10.2 & 10.2 \\
\hline & Local Roads Thickness $(\mathrm{cm})$ & 7.6 & 7.6 & 7.6 \\
\hline \multirow{5}{*}{ Granular Base } & Elastic Modulus (MPa) & 207 & 207 & 207 \\
\hline & Interstate Thickness $(\mathrm{cm})$ & 38.1 & 38.1 & 38.1 \\
\hline & National Route Thickness $(\mathrm{cm})$ & 20.3 & 20.3 & 20.3 \\
\hline & State Route Thickness $(\mathrm{cm})$ & 15.2 & 15.2 & 15.2 \\
\hline & Local Roads Thickness (cm) & 12.7 & 12.7 & 12.7 \\
\hline \multirow{4}{*}{ Subgrade } & AASHTO Classification & A-2-4 & A3 & A-4 \\
\hline & Description & Silty Sand & Fine Sand & Silty Soil \\
\hline & Elastic Modulus (MPa) & 134 & 152 & 62 \\
\hline & Water Table (m) & 15.2 & 3.4 & 16.8 \\
\hline \multirow{3}{*}{$\begin{array}{l}\text { Interstate } \\
\text { Traffic }\end{array}$} & Truck Traffic Classification ${ }^{2}$ & 1 & 1 & 1 \\
\hline & Speed $(\mathrm{km} / \mathrm{h})$ & 97 & 97 & 97 \\
\hline & Cumulative Truck Traffic & $3,590,500$ & $3,801,700$ & $1,056,030$ \\
\hline \multirow{3}{*}{$\begin{array}{c}\text { National } \\
\text { Route Traffic }\end{array}$} & Truck Traffic Classification $^{2}$ & 4 & 4 & 4 \\
\hline & Speed $(\mathrm{km} / \mathrm{h})$ & 97 & 97 & 97 \\
\hline & Cumulative Truck Traffic & $1,267,230$ & $1,689,650$ & 190,085 \\
\hline \multirow{3}{*}{$\begin{array}{l}\text { State Route } \\
\text { Traffic }\end{array}$} & Truck Traffic Classification $^{2}$ & 14 & 14 & 14 \\
\hline & Speed $(\mathrm{km} / \mathrm{h})$ & 72 & 72 & 72 \\
\hline & Cumulative Truck Traffic & 704,019 & $1,642,710$ & 70,401 \\
\hline \multirow{3}{*}{$\begin{array}{l}\text { Local Road } \\
\text { Traffic }\end{array}$} & Truck Traffic Classification $^{2}$ & 17 & 17 & 17 \\
\hline & Speed $(\mathrm{km} / \mathrm{h})$ & 48 & 48 & 48 \\
\hline & Cumulative Truck Traffic & 352,010 & 938,693 & 32,854 \\
\hline
\end{tabular}

${ }^{1}$ Weather station name and (number) from AASHTO Pavement Design ME software

${ }^{2}$ Truck Traffic Classification (TTC) are general distributions of trucks; 1 = Major single-trailer truck routes (Type I) I), 4 = Major single-trailer truck routes (Type III), 14 = Major light truck route (Type I), 17 = Heavy bus route 